\title{
Large-scale spatio-temporal monitoring highlights hotspots of demersal fish diversity in the Mediterranean Sea
}

\author{
Granger Victoria ${ }^{1,{ }^{*}}$, Fromentin Jean-Marc ${ }^{2}$, Bez Nicolas ${ }^{3}$, Relini Giulio ${ }^{4}$, Meynard Christine ${ }^{5,6}$, \\ Gaertner Jean-Claude ${ }^{7}$, Maiorano Porzia ${ }^{8}$, Garcia Ruiz Cristina ${ }^{9}$, Follesa Cristina ${ }^{10}$, Gristina Michele \\ ${ }^{11}$, Peristeraki Panagiota ${ }^{12}$, Brind'Amour Anik ${ }^{13}$, Carbonara Pierluigi ${ }^{14}$, Charilaou Charis ${ }^{15}$, Esteban \\ Antonio ${ }^{16}$, Jadaud Angelique ${ }^{2}$, Joksimovic Aleksandar ${ }^{17}$, Kallianiotis Argyris ${ }^{18}$, Kolitari Jerina ${ }^{19}$, \\ Manfredi Chiara ${ }^{20}$, Massuti Enric ${ }^{21}$, Mifsud Roberta ${ }^{22}$, Quetglas Toni ${ }^{21}$, Refes Wahid ${ }^{23}$, Sbrana Mario \\ ${ }^{24}$, Vrgoc Nedo ${ }^{25}$, Spedicato Maria Teresa ${ }^{14}$, Mérigot Bastien ${ }^{1}$
}

${ }^{1}$ Université de Montpellier 2, UMR 212 Ecosystèmes Marins Exploités (EME), Centre de Recherche halieutique Méditerranéenne et Tropicale, 34203 Sète, France

${ }^{2}$ Institut Français de Recherche pour l'Exploitation de la Mer (Ifremer), UMR 212 Ecosystèmes Marins Exploités (EME), Centre de Recherche halieutique Méditerranéenne et Tropicale, 34203 Sète, France

${ }^{3}$ Institut de Recherche pour le Développement (IRD), UMR 212 Ecosystèmes Marins Exploités (EME), Centre de Recherche halieutique Méditerranéenne et Tropicale, 34203 Sète, France

${ }_{5}^{4}$ Dipartimento di Scienze della Terra, dell'Ambiente e della Vita (DISTAV), 16132 Genova, Italy

${ }^{5}$ Institut National de la Recherche Agronomique (INRA), UMR Centre de Biologie pour la Gestion des Populations (CBGP), CS 30016, Montferrier-sur-Lez, France

${ }^{6}$ Virginia Institute of Marine Science, College of William \& Mary, VA 23062-1346, USA

${ }^{7}$ Institut de Recherche pour le Développement (IRD), UMR 241 Ecosystèmes Insulaire Océanique (EIO), Centre d'Arue, Papeete, Tahiti, Polynésie française

${ }_{9}^{8}$ Department of Biology, University of Bari, Bari, Italy

9 Instituto Español de Oceanografía (IEO), Centro Oceanográfico de Málaga, Fuengirola, Málaga, Spain

${ }_{11}^{10}$ Dipartimento di Biologia Animale ed Ecologia, Universita di Cagliari, Cagliari, Italy

11 Institute for the Coastal Marine Environment (CNR), Mazara del Vallo, Italy

${ }^{12}$ Hellenic Center for Marine Research, Iraklion, Crete, Greece

${ }^{13}$ Institut Français de Recherche pour l'Exploitation de la Mer (Ifremer), Département Ecologie et Modèles pour l'Halieutique (EMH), 44311 Nantes, France

${ }^{14}$ COISPA Tecnologia and Ricerca, Stazione Sperimentale per lo Studio delle Risorse del Mare, Bari, Italy

${ }^{15}$ Department of Fisheries and Marine Research, Ministry of Agriculture, Natural Resources and

Environment, Nicosia, Cyprus

${ }_{17}^{16}$ Instituto Español de Oceanografía (IEO), Centro Oceanográfico de Murcia, Murcia, Spain

17 Institute of Marine Biology, University of Montenegro, 85330 Kotor, Montenegro

${ }_{18}^{18}$ Fisheries Research Institute, National Agricultural Research Foundation, Kavala, Greece

${ }^{19}$ Aquaculture and Fishery Laboratory Durres, Agricultural University Tirana, Durres, Albania

${ }^{20}$ Laboratorio di Biologia Marina e Pesca di Fano, Dip.to B.E.S., Università di Bologna, Fano, Italy

${ }^{21}$ Instituto Español de Oceanografía (IEO), Centro Oceanográfico de les Balears, Palma, Spain

${ }^{22}$ Department of Fisheries and Aquaculture, Ministry for sustainable development, the environment and climate change (MSDEC), Marsa, Malta

${ }^{23}$ Ecole Nationale Supérieure des Sciences de la Mer et de l'Aménagement du Littoral (ENSSMAL), Alger, Algérie 
${ }_{25}^{24}$ Consorzio per il Centro Interuniversitario di Biologia Marina ed Ecologia Applicata, Livorno, Italy

${ }^{25}$ Institute of Oceanography and Fisheries, Split, Croatia

* Corresponding author : Victoria Granger

\begin{abstract}
:
Increasing human pressures and global environmental change may severely affect the diversity of species assemblages and associated ecosystem services. Despite the recent interest in phylogenetic and functional diversity, our knowledge on large spatio-temporal patterns of demersal fish diversity sampled by trawling remains still incomplete, notably in the Mediterranean Sea, one of the most threatened marine regions of the world. We investigated large spatio-temporal diversity patterns by analysing a dataset of 19,886 hauls from 10 to $800 \mathrm{~m}$ depth performed annually during the last two decades by standardized scientific bottom trawl field surveys across the Mediterranean Sea, within the MEDITS program. A multi-component (eight diversity indices) and multi-scale (local assemblages, biogeographic regions to basins) approach indicates that only the two most traditional components (species richness and evenness) were sufficient to reflect patterns in taxonomic, phylogenetic or functional richness and divergence. We also put into question the use of widely computed indices that allow comparing directly taxonomic, phylogenetic and functional diversity within a unique mathematical framework. In addition, demersal fish assemblages sampled by trawl do not follow a continuous decreasing longitudinal/latitudinal diversity gradients (spatial effects explained up to $70.6 \%$ of deviance in regression tree and generalized linear models), for any of the indices and spatial scales analysed. Indeed, at both local and regional scales species richness was relatively high in the Iberian region, Malta, the Eastern Ionian and Aegean seas, meanwhile the Adriatic Sea and Cyprus showed a relatively low level. In contrast, evenness as well as taxonomic, phylogenetic and functional divergences did not show regional hotspots. All studied diversity components remained stable over the last two decades. Overall, our results highlight the need to use complementary diversity indices through different spatial scales when developing conservation strategies and defining delimitations for protected areas.
\end{abstract}

\title{
Highlights
}

-We analyse fish diversity by a multiple indices and scales approach over 19 years. Species richness and evenness are proxies of phylogenetic and functional components. Species richness reveals hotspots for different spatial scales contrary to evenness. All diversity components remains stable over the last two decades.

Keywords: Functional diversity, Phylogenetic diversity, Rao's quadratic entropy, Regression tree, Large scale 
Introduction

Both terrestrial and marine biodiversity suffer from multiple impacts by ever increasing direct human pressure and global environmental change (Coll et al., 2012, Halpern et al., 2008 and Thuiller et al., 2011). Such disturbances may affect the diversity of species assemblages (Coll et al., 2012 and D'agata et al., 2014). It can be monitored through the assessment of different components, or facets, such as species number, evenness and taxonomic, phylogenetic or functional diversity that take into account the degree of difference among species. These components enable the characterization of species in terms of their evolutionary history (Webb et al., 2002) or their functional role on the basis of their traits (McGill et al., 2006). Recent proposals for measuring assemblage diversity have aimed to include these biological differences among species into complementary diversity indices (Cadotte et al., 2010, D'agata et al., 2014, Lefcheck et al., 2014, Schleuter et al., 2010 and Stuart-Smith et al., 2013). Notably, it has been shown that phylogenetic and functional diversity can be complementary in assessing changes in the functioning of an ecosystem in response to external disturbances (Cadotte et al., 2009 and D'agata et al., 2014), and even more sensitive to human pressure than species richness (D'agata et al., 2014). To date, studies at large spatio-temporal scales based on standardized field surveys remain scarce due to the associated logistical difficulties and costs related to the collection of species abundance data, creating phylogeny and/or measuring 
functional traits, particularly in the marine domain (D'agata et al., 2014; Gaertner et al., 2013;

Stuart-Smith et al., 2013).

Due to its geological evolution and environmental conditions, the Mediterranean Sea is characterized by relatively high biodiversity (Coll et al., 2010). At the same time, it is one of the world's most threatened marine regions (Ben Rais Lasram et al., 2010; Coll et al., 2012, 2010). These threats result from a combination of various drivers such as pollution, habitat loss, introduction of new species, climate change and exploitation (Coll et al., 2012). They might have impacted the structure and composition of species assemblages, notably those of demersal fish targeted by intensive bottom trawling for commercial fishing (GFCM, 2012; Rochet et al., 2010). However, a study focused on demersal fish diversity sampled by trawling on the continental shelf and slope, based on species abundance data from standardized scientific surveys at large spatial and temporal scales in the Mediterranean Sea, is lacking. Previous studies exploring fish diversity at large scale in this area have provided insights based on gridded species presence-absence maps drawn on the basis of expert-based knowledge (e.g. (Ben Rais Lasram et al., 2009; Coll et al., 2012; Mouillot et al., 2011) or on abundance data collected by visual census (e.g. (Guidetti et al., 2014; Stuart-Smith et al., 2013). These works did not necessarily focus on demersal fish assemblages, or use the same sampling methodology (i.e. trawling), and could not investigate temporal trends. Elsewhere, species richness has been the focus of fish diversity assessments in the Mediterranean Sea (e.g. (Ben Rais Lasram et al., 2009; Coll et al., 2012)), as is usually the case worldwide. Very few works have considered phylogenetic and/or functional fish diversity at large scale in this area (e.g. (Mouillot et al., 2011; Stuart-Smith et al., 2013)). Most of the available studies performed on coastal and continental shelf fish assemblages showed that the spatial pattern of 
fish diversity is not homogenous over the entire Mediterranean basin, with a decreasing northwest /south-east gradient of species richness and phylogenetic diversity (Coll et al., 2012; Mouillot et al., 2011), and north-south gradient of functional diversity (Mouillot et al., 2011) (see however (Guidetti et al., 2014) for species richness sampled by visual census). The patterns, notably for species richness, are assumed to be related to a gradient in primary productivity (i.e. the rate at which energy is converted per unit area by photosynthetic and chemosynthetic autotrophs to organic substances (Begon et al., 2006)), which is inversely related to an increase in temperature and salinity (Coll et al., 2012). However, as highlighted by the these authors, sampling effort is known to be much lower in the southern and eastern regions and could thus bias the observed patterns of diversity (Coll et al., 2012). Studies dedicated to demersal fishes sampled by trawling within scientific surveys performed at large scale over the northern Mediterranean Sea did not find a west-east decreasing gradient for species richness, evenness and taxonomic diversity (Gaertner et al., 2007, 2013). Their analyses revealed no temporal patterns, but were restricted to a short temporal window (i.e. 4/3 years, 1996 to 1999/1998 respectively).

Thus, despite the recent interest in functional and phylogenetic diversity and previous studies dedicated to fish diversity in the Mediterranean Sea, our knowledge of large-scale spatial and temporal patterns of demersal fish diversity sampled by trawling in this area is still incomplete. The aim of this study is to analyze its diversity patterns using complementary indices on the basis of abundance data collected by trawling from 1994 to 2012 within a standardized scientific protocol over the northern Mediterranean but also Algeria and the eastern part of the Mediterranean Sea, which has hitherto been poorly sampled (Coll et al., 2012), and/or not included in standardized field surveys at large scale. The present study 
treats a data set of 19,886 sampled hauls performed on more than $20,000 \mathrm{~km}$ of coastline for a bathymetry of $10-800 \mathrm{~m}$. More specifically, the main steps of our study are: i) to quantify to what extent taxonomic, phylogenetic and functional components provide different information on demersal fish species, ii) to investigate relationships (complementarity/redundancy) between indices of assemblages diversity, iii) to analyse temporal trends of demersal fish diversity over the last two decades, and iv) to identify, for different spatial scales over the Mediterranean Sea, groups of areas according to their diversity level (i.e. hotspots).

\section{Materials and methods}

\subsection{Survey methods and data collection}

The data was collected from annual bottom trawl surveys performed in May-July (except February, in Algeria) from 1994 to 2012 over the continental shelf (10 m to $200 \mathrm{~m}$ depth) and the continental slope (200 m to $800 \mathrm{~m}$ ) of the Mediterranean Sea within the framework of the MEDITS scientific program (Bertrand et al., 2002). Our study area ranged from $34.5^{\circ} \mathrm{N}$ to $45.7^{\circ} \mathrm{N}$ and $5.3^{\circ} \mathrm{W}$ to $34.1^{\circ} \mathrm{E}$ and was divided into 18 operative Geographical Sub-Areas (GSAs), for which boundaries were established by the General Fisheries Commission for the Mediterranean Sea (www.gfcm.org, see Fig. 1 for the correspondence between GSA numbers and their names). The sampling procedures were standardized according to a common protocol over GSAs and years. The standard device was a bottom trawl GOC-73 with 20-mm cod-end mesh size. The average vertical opening of the gear was $2 \mathrm{~m}$ and its wing-span $18 \mathrm{~m}$. All the tows were performed during daylight hours. Speed on the ground and duration of the tows were standardized to 3 knots and $30 \mathrm{~min}$ for shelf stations (10-200 m), and $60 \mathrm{~min}$ for upper slope, respectively (200-800 m) (see (Bertrand et al., 2002) for full details). For each haul we collected raw fish abundance data, bathymetry, swept area (i.e. trawled surface) and 8 
haul coordinates. Information recorded by an underwater Scanmar system - to control the trawl geometry (horizontal and vertical openings, contact with the bottom) - as well as recorded swept area and trawling time, enabled us to select the tows that were properly carried out. The hauls in which only one or two fish species were caught and where their abundance was extremely low (total abundance below the first quartile, i.e. 133 individuals per haul) were excluded from analyses to remove potentially inoperative hauls. These hauls represented less than $3 \%$ of the total sampled hauls and were equally distributed over the study area. Overall, these selections of properly carried out hauls enabled us to perform accurate diversity comparisons over GSAs and years to avoid bias from different sampling effort among hauls. Among a total of 348 species sampled during surveys, we considered 186 species properly sampled by the bottom trawl system used, and properly identified by teams involved in this large scale program (Gaertner et al., 2013,2010). This subset of 186 demersal fishes (i.e. benthic and bentho-pelagic fishes) was designed in such a way as to minimize potential bias caused by gear-selectivity (e.g. (Lefcheck et al., 2014; Villéger et al., 2010)), and to strictly limit the risk of a variability of accuracy in sampling identification between the different teams. The list of 186 species considered was set according to those used in (Gaertner et al., 2013, 2010) (see Appendix A for the list of species considered). Raw abundance data was normalized by the trawl surface, and the resulting species densities were used for indices computation. Some years for some GSAs were excluded when species identification during surveys was restricted to a specific spectrum of species and thus biased assemblage diversity assessment. After cleaning up the data as described above, a total of 19,886 accurate sampled hauls were chosen from 1994 to 2012 (representing 97\% of available hauls).

\subsection{Diversity indices


We used eight species diversity indices to assess the main diversity components of demersal fish assemblages' diversity. Species richness $(S)$, measuring the number of species in an assemblage (i.e. haul) and still the most widely used diversity index, was computed. We also used the Simpson evenness index 1-D/(1-1/S) (Smith and Wilson, 1996), where $D=\sum_{i=1}^{S} p_{i}^{2}$ with $p_{i}$ is the relative abundance of the $i^{t h}$ species, Simpson $D$ index being an heterogeneous index combining species richness and evenness (Simpson, 1949). Measures of taxonomic, phylogenetic and functional diversity were based on two versions of Rao's quadratic entropy index. First, on the basis of abundance data, Rao's quadratic entropy index $(Q)$ provided a unifying calculation to investigate and compare from the same mathematical formula taxonomic, phylogenic, and functional divergences (TD/PD/FD) (Lefcheck et al., 2014; Mason et al., 2005; Pavoine, 2012; Rao, 1982). This has been successfully used in both terrestrial and marine analysis (Devictor et al., 2010; Lefcheck et al., 2014; Mouillot et al., 2011; Stuart-Smith et al., 2013). This index is defined as:

$$
Q=\sum_{i=1}^{S} \sum_{j=1}^{S} p_{i} p_{j} d_{i j}
$$

where $p_{i}$ and $p_{j}$ are the relative abundance of the $i^{\text {th }}$ and $j^{\text {th }}$ species, $d_{i j}$ the taxonomic, phylogenetic, or functional difference between two species $i$ and $j$ stored in a distance matrix. Note that in the case of all $d_{i j}=1$ for every species pairs, this index is similar to the Simpson diversity index $1-D$.

Next, we also computed Rao's quadratic entropy on the basis of presence/absence data to quantify taxonomic, phylogenetic and functional richness $(T R / P R / F R)$. This index allowed the evenness component to be excluded. We employed a corrected version of this index, defined by Izsak \& Papp (Izsak and Papp, 2000): 


$$
Q^{+}=\sum_{i=1}^{S} \sum_{j=1}^{S} d_{i j}
$$

This corresponds to the sum of pair-wise taxonomic, phylogenetic or functional distances between species in an assemblage. As for any diversity index, it presents some limitations (Schmera et al., 2007) but it has the advantage of being computed on the initial $d_{i j}$, i.e. without distortion of the initial information, in contrast to other existing functional diversity indices that are based on species distances from clustering methods computed on $d_{i j}$ (e.g (Mérigot et al., 2010; Petchey and Gaston, 2002)). In addition, if all species are strictly similar/redundant (from a phylogenetic or functional point of view), each $d_{i j}$ and $Q^{+}$equal 0. It results that $d_{i j}$, and in turn $Q^{+}$, increases with the complementarity between two species. Thus, this index will be naturally and logically positively correlated to species richness, to a greater or lesser extent depending on species redundancy. Functional diversity can also be investigated separately by specific indices (e.g. (Villéger et al., 2008)) that we also considered but which are not appropriate for taxonomic and phylogenetic diversity (see Appendix B, Part B1, Fig. B1 and B2). Otherwise, diversity indices can be computed within the recent framework of "effective species number" ((Jost, 2006), see Appendix B, Part B2).

Because index values are scale-dependent, here we analyzed spatial diversity patterns at different spatial scales: GSA ( $m=18$ modalities), biogeographical zones $(m=7)$ and basin $(m=$ 2) (see Fig. 1). For each spatial unit (e.g. the 18 different GSAs) and for each year, we computed indices values by measuring i) haul diversity (i.e. $\alpha$-diversity) and ii) total diversity over the hauls (i.e. $\gamma$-diversity) (Lande, 1996; Whittaker, 1972). Boundaries of GSAs correspond to those established by the General Fisheries Commission for the Mediterranean (www.gfcm.org, see above), while boundaries for basins or biogeographical zones are those 
defined in previous studies of species diversity patterns (Gaertner et al., 2007, 2013). In addition, species richness $S$ per spatial unit is sensitive to the sampling effort, notably at GSA scale, and because the number of hauls performed was variable between GSAs-years (i.e. between 13 and 182 hauls), the comparison between $S$ values per GSA was done on rarefied values to avoid bias, with $S$ per GSA rarefied to 25 hauls (i.e. $S$ deduced from the rarefaction curve of each GSA at 25 hauls) resulting in the exclusion of 19 GSAs-year. This number was an accurate compromise knowing that a lesser number of hauls led to a higher standard deviation associated with the mean rarefied species richness values, and a higher number of hauls would lead to the exclusion of years of GSA with a lower sampling effort. In addition, outcomes of statistical procedures with other rarefaction levels $(15,30,35$ hauls) underlined similar richness patterns (not shown). In contrast to $S$, Rao's quadratic entropy $Q$ was not sensitive to sampling effort (no relation was observed between the $\gamma$-values and the number of sampled hauls per GSA). Consequently this index was not rarefied.

\subsection{Taxonomic, phylogenetic and functional distances}

Three distinct data sources were used to establish taxonomic, phylogenetic and functional distances, as is traditionally done for different species groups worldwide (e.g. (D'agata et al., 2014; Devictor et al., 2010; Lefcheck et al., 2014; Mouillot et al., 2011)).

For taxonomic richness and divergence ( $T R$ and $T D$ respectively), distances between species were constructed using the Linnaean taxonomic classification (e.g. (Lefcheck et al., 2014)). The distance between two species from the same genus was set to 1, two species from the same family but different genus was 2 , same order but different genus and family was 3 , and so on. We considered a taxonomy including 5 levels (species, genus, family, order and class). For functional richness and divergence ( $F R$ and $F D$ respectively), pairwise distances between the 186 fish species were computed from 11 morphological traits measured in the field and on 12 
pictures, by mean of the ImageJ software (http://imagej.nih.gov/ij/), taken during 2011 and 2012 MEDITS surveys. For a given species, each continuous trait was computed from the mean values of about ten individuals. Within demersal fish assemblages, some species are rare, preventing them from being caught several times during annual surveys. For these rare fish species that were not caught during these two surveys, we were constrained to consider one individual per species with pictures found at Fishbase (Froese and Pauly., 2011), selecting only those from the Mediterranean Sea. These morphological traits were related to food acquisition and locomotion, two main functions of fish closely related to feeding and habitat use (Albouy et al., 2011) (see Appendix C for the list of functional traits used in this study). We then selected complementary traits with low correlation (Pearson correlation coefficient $r$ $<0.5$ ), leading to exclusion of a single trait (i.e. the horizontal oral gap trait which was highly correlated to vertical oral gap trait, $r=0.94)$ from further analysis. Since functional traits were a set of mixed variable types, i.e. either quantitative (continuous) or qualitative (nominal and ordinal), Gower's coefficient was applied to compute functional distances between species (Gower, 1971).

For phylogenetic richness and divergence ( $P R$ and $P D$ respectively), we used the phylogeny of 134 osteichthyes Mediterranean fish (representing 72\% of the demersal species published in (Meynard et al., 2012)). This phylogeny was based on mitochondrial and nuclear genes, and was calibrated using fossil records (see (Meynard et al., 2012) for more details).

Statistical analyses below were thus focused on 134 demersal osteichthyes, among the initial 186 species, for which phylogeny is only available (not for 52 species, i.e. 39 elasmobranchs and 13 osteichthyes species). 
The three types of distances (taxonomic, functional and phylogenetic) were normalized between 0 and 1 by their respective maximum to be able to compare the three divergence and richness indices among them.

\subsection{Statistical analysis}

To compare and determine to what extent taxonomic, phylogenetic and functional components are complementary at the species level, we represented the plots of their pairwise distance matrices. We studied the dispersion of the species distances scatter plots (graphically and by mean of Pearson's correlation coefficient), and its lag from the first bisector representing the case for which the two matrices are identical.

To investigate the redundancy/complementarity of the different diversity indices computed for each haul (i.e. at the assemblage level), we used a Draftsman's plot and Pearson's correlation coefficients. This coefficient was preferred to non-parametric ones $(e . g$. Spearman) due to monotonic linear relationships between some indices. The Draftsman's plot, which represents the pairwise relationships among all indices in the same plot, allows selection of only non-correlated indices for further analyses, i.e. those which are complementary in their response at the assemblage level.

Finally, we investigated diversity patterns at different spatial scales (i.e. 18 GSAs, 7 biogeographical zones or 2 basins) through time (i.e. 19 years) by two complementary analyses: generalized linear models (GLM, (McCullagh and Nelder, 1989)) and regression trees (CART, (Breiman et al., 1984)). In both cases, the diversity indices were used as the response variable, while year and spatial variables (GSAs, biogeographical zones or basins) were used as explicative factors. In preliminary analysis, we also considered depth as a covariate in GLMs for $\alpha$-diversity, and its effect was low (around 4.9\%). In case of GLM for $\gamma$-diversity, bathymetry is not accurate enough to be included because an entire spatial unit is 14 
considered. GLM was implemented to quantify the global deviance explained by year and spatial factors, the part of this deviance attributed to each factor, as well as their potential interaction, while dealing with non-normal distributions. In complement, CART was applied to identify areas with similar levels of diversity while selecting automatically relevant explicative factors (i.e. spatial and year factors).

Assumptions on Poisson conditional distributions and goodness of fit for GLMs were checked by complementary graphical diagnostics (normality of standardized residuals by using a quantile-quantile plot, homogeneity by plotting standardized residuals against fitted values, influence of values in the estimation of model parameters by Cook's distance and leverage effect).

Assessment of semi-variograms on residuals of mixed-effect GLMs for $S$ and $F D$ (values per haul) indicated that spatial autocorrelation was low at Mediterranean level, even if significant (due to the high number of observations). Residuals showed a spatial autocorrelation at small distances (within GSAs) for some GSAs, and varied according to the GSA considered. Thus different modelled (i.e. theoretical) variograms would have been needed for each GSA or groups of them. However, this implementation in a common model at the scale of the study, which aims to compare GSAs, is not yet possible with existing tools (Pinheiro and Bates, 2000).

All diversity indices and statistical analyses mentioned above were performed using R 3.0.1 software (R Core Team, 2013).

\section{Results}

\subsection{Relationships between taxonomy, phylogeny and functional diversity}

Scatter plots between phylogenetic, taxonomic and functional distance matrices for the 134 osteichtyes fish species (not for the 186 species as phylogenetic information for 52 species is 15 
not available, see 2.3. of the Material and Methods section) suggest that each diversity component provides different information on demersal fish species (Fig. 2). The overlap between functional information with phylogenetic/taxonomic information is very low, according to a high dispersion of the pairwise distance scatter plots and low Pearson's correlation values $(0.24<r<0.25)$. A high dispersion of the scatter plot between taxonomic and phylogenetic components can also be observed, even if the overlap and the correlation is higher in that case $(r=0.67)$. These mismatches are also underlined by the lag of the scatter plots to the first bisector. Overall, these results show that all three components are complementary at the species level, i.e. that demersal species are not equally distant according to the information considered.

The correlation between diversity components at the assemblage/haul level was studied by mean of correlations between all pairs of indices computed for each haul (Fig. 3). First, Simpson evenness and divergence indices $T D, P D$ and $F D$ (computed by Rao's quadratic entropy $Q$ ) display similar density distributions and are highly correlated to each other (Pearson's index: $0.72<r<0.96$, Fig. 3). In other words, there was very little difference in patterns between these indices, all linked to the evenness component. Indeed, $T R / F R / P R$ computed by Rao's quadratic entropy $Q+$ (based on presence/absence data to remove the contribution of evenness) were not correlated to $T D / P D / F D(0.11 \leq r \leq 0.2)$, but strongly correlated to each other $(r \geq 0.98)$ and to $S$ ( $r \geq 0.99)$. Finally, Simpson evenness (as well as $T D, P D, F D)$ and $S$ provide complementary information on the response of demersal fish diversity at the assemblage/haul level $(0.16<r<0.2)$. Considering these results, subsequent analyses will focus on $S$ and $F D$, which provided different responses in patterns of demersal fish assemblage diversity. Between Simpson evenness and the different divergence indices 
$T D, P D, F D$, we choose $F D$ because no study for the Mediterranean has to date provided a large-scale spatio-temporal analysis of functional diversity based on abundance and on species traits measured on demersal fish individuals sampled by trawling during scientific surveys.

Note that pairwise relationships between indices per haul were also computed on the list of 186 species (i.e. both osteichthyes and chondrichthyes for which a common phylogeny is not yet available, see 2.3. of the Material and Methods section). Similar results were obtained (Appendix D, Fig. D1), suggesting that the above analyses and results focusing only on osteichthyes were representative for taxonomic and functional diversity patterns.

\subsection{Spatio-temporal patterns of demersal fish diversity}

We analyzed spatial diversity patterns at different spatial scales, i.e. GSA, biogeographical zone and basin, using two levels of diversity, i.e. $\alpha$-diversity (the diversity measured in each haul) and $\gamma$-diversity (the total diversity of the spatial unit of interest), rarefied for species richness values. Hereafter, we focused on the analyses made at the scale of the GSAs because corresponding models displayed the highest values of explained deviance for both species richness $S$ and functional divergence $F D$ (see Appendix E for analyses performed at the scales of the biogeographical zone and basin).

\subsubsection{Species richness $S$}

Our results indicate a spatial differentiation both at local and regional scales and a temporal stability of $S$. Firstly, the GLM regressing $S$ per haul ( $\alpha$-diversity) against the GSAs/years explained $18.9 \%$ of the deviance (Tab.1). A significant regional differentiation by $S$ was observed in the Mediterranean area $(\sim 10.5 \%$ of deviance, $\mathrm{p}<0.001)$. The effect of year, even 
if significant, was very weak $(<2 \%$ of deviance, $\mathrm{p}<0.001)$. Nonetheless, interaction between spatial and temporal factors explained $6.7 \%$ of the model deviance $(\mathrm{p}<0.001)$, being significant for some GSAs. Regression tree based on $S$ per haul explained $9.2 \%$ of the total variance, with a single split of two groups of GSAs based on spatial partitioning: i) Iberian Gulf of Lions area, eastern Ionian Sea, Aegean Sea and Malta (mean of 19.7 \pm 5.3 species per haul, standard deviation), and ii) central Mediterranean GSAs (Adriatic Sea and western Italian areas), Algeria and Cyprus (mean of 16.3 \pm 4.8 species per haul, Fig. 4.a, Fig 5.a). Secondly, the GLM regressing rarefied $S$ per GSA ( $\gamma$-diversity) against the same co-variables explained a much greater part of the variability (about $76.8 \%$ of the deviance). Spatial differentiation still explained the bulk of the deviance $(70.6 \%, \mathrm{p}<0.001)$, while the contribution of temporal variability is still weak even if significant $(6.2 \%, \mathrm{p}<0.05)$. Interaction could not be quantified because there was only one value of $S$ per GSA and per year. Similarly, the regression tree model based on $\gamma$-diversity explained $65.9 \%$ of the total variance (Fig 5.b), with temporal stability and spatial partitioning. Overall, this model identified 4 main areas based on rarefied $S$ (Fig 4.b and 5.b): i) northern Adriatic Sea (mean of 65.8 \pm 5.5 species), ii) Cyprus, southern Adriatic Sea and Gulf of Lions (76.3 \pm 6.4 species), iii) Algeria, Iberian area, western and southern Italian areas, Malta, Aegean and Cretan seas (85.9+5.1 species), iv) Baleares and eastern Ionian Sea (97.9 \pm 5.4 species). To sum up, statistical analysis (regression tree models and GLMs) showed that species richness $S$ is mostly spatially structured; however it does not display a longitudinal gradient for any of the investigated scales (see also Appendix E, Fig E1, Table E1). At both scales, we also underlined the temporal stability of $S$ patterns during the last two decades.

\subsubsection{Functional divergence $F D$}


$F D$ values computed per haul ( $\alpha$-diversity) and total regional diversity ( $\gamma$-diversity) for each GSA followed both asymmetric left skewed distributions (Fig.3). Thus, a simple value transformation $(1-F D)$ allowed an exponential family distribution to be achieved to implement a GLM. In both cases, according to the residual analysis, gamma distribution was found to be the most appropriate among this distribution family.

In contrast to the results we obtained on $S$, GLM showed that functional divergence was temporal and spatially stable, for both values by haul or by GSA, explaining only $\sim 7 \%$ and $\sim 10.5 \%$ of the deviance, respectively (Tab.1). Similarly, in both cases, regression trees computed on 1-FD did not provide strong and specific groups of GSAs/years (not shown), highlighting a stability of $F D$ over all GSAs and years studied, with absence of longitudinal gradients in functional divergence. However, $F D$ was highly heterogeneous within each GSA (see Appendix E, Fig. E2).

In short, our results underlined hotspots for species richness at both local and regional scales. In contrast, functional divergence did not show regional hotspots. For both indices, there was an absence of an eastwards/southwards decreasing diversity gradient, and high temporal stability during the last two decades (and by extension for the 6 other indices considered in this study, each of them being strongly correlated with $S$ or $F D$, see above).

\section{Discussion}

\subsection{Complementarity between diversity components and indices}

For demersal Mediterranean fishes, our analyses at species level support the idea that information provided by taxonomic, phylogenetic and functional diversity components are different and complementary. While several studies have suggested the use of existing Linnaean taxonomy as a proxy for phylogeny (see references in (Lefcheck et al., 2014)), our 
study suggests that taxonomic distances may not fully reflect evolutionary relationships drawn by molecular phylogeny (Crozier et al., 2005). Indeed, discrete taxonomic levels (i.e. genus, family, etc.) limit the resolution of species differences compared to those derived from continuous DNA sequence variation. Furthermore, the stronger mismatch between species function and phylogeny is in agreement with a recent meta-analysis demonstrating that phylogenetic differences between species (i.e. evolutionary history) does not necessarily capture functional differences (Kelly et al., 2014). Overall, the assumption that traits are correlated or predicted by phylogeny, in part stems from the widely held thought that Linnaean taxonomy is predictive of features of organisms (see references in (Kelly et al., 2014)), and might not hold for the demersal Mediterranean fishes. Therefore, considering taxonomic, phylogenetic and functional data might be an accurate way to describe species differences of demersal Mediterranean fishes.

At the haul scale, we found that the use of two indices is sufficient for evaluating patterns in phylogenetic, functional or taxonomic richness and divergence, and that species richness and evenness can provide good proxies for demersal fish assemblages sampled by trawling in the Mediterranean Sea. Strong correlations between the divergence indices corroborate a recent proposal to use only one of them as a suitable proxy (Lefcheck et al., 2014). Taxonomical divergence has been suggested by some authors, because species taxonomy is generally fully available and does not require more intensive collection of functional traits and phylogenetic data (Lefcheck et al., 2014), knowing that phylogenetic and functional data require intensive experimentation and computation, and are thus costly and time-consuming. Its use as a proxy is thought to be suitable when the evolutionary relationships between species are well delineated by taxonomy (Lefcheck et al., 2014; Ricotta et al., 2012), especially when using detailed taxonomy to translate evolutionary distances (Lefcheck et al., 2014). In a counter- 
intuitive way, even if taxonomy does not capture the phylogenetic or functional signals, divergence indices can be highly correlated because they are mostly driven by species relative abundance (i.e. Simpson evenness index (Smith and Wilson, 1996)). This is confirmed by the decomposition of $Q$ proposed by (Pavoine et al., 2013) to identify the main driving forces of this index (see Appendix F). Thus, in our case, species evenness describes the trends of divergences indices.

The correlation between divergence indices has been also studied in other previous studies (Devictor et al., 2010; Lefcheck et al., 2014; Mouillot et al., 2011) ; however, their results are not directly comparable with our findings being based on different data (e.g. presence/absence data at resolution of $0.1^{\circ} \times 0.1^{\circ}$ established by expert knowledge, and not necessarily targeting the same groups of fishes and/or with the same sampling methodology), different spatial scales as well as different mathematical versions of the quadratic entropy index $(\gamma, \beta$ levels in the context of diversity decomposition paradigm, e.g. (Devictor et al., 2010; Meynard et al., 2011)).

To sum up, the correlation analysis between the different diversity indices led us to select only two diversity indices for the demersal fish assemblages studied, confirming the need to use several indices for fish diversity assessment, as previously advocated (e.g. (D'agata et al., 2014; Gaertner et al., 2013, 2010; Mérigot et al., 2007; Stuart-Smith et al., 2013)). However, the implementation of widely used richness and divergence indices that would allow comparison of taxonomic, phylogenetic and functional diversity within a single mathematical framework is not supported. Finally, our results support the framework of a shortlist of diversity indices proposed by (Gaertner et al., 2010) for investigating the multi-component aspect of demersal diversity to facilitate large scale studies and their comparison (Gaertner et al., 2013; Lefcheck et al., 2014). 


\subsection{Spatio-temporal patterns of demersal fish diversity}

Species richness $S$ showed relatively low levels of diversity in the Adriatic Sea and Cyprus, and relatively high levels in the eastern Ionian and Aegean seas, Iberian region and Malta at both local and regional scales. In contrast to $S$, divergence indices, and therefore evenness, remained spatially stable between spatial areas (GSAs). Thus, whatever the diversity index used and the spatial scales considered, diversity patterns of demersal fish assemblages sampled by trawling in the continental shelf and slope differ from studies dedicated to the Mediterranean coastal and continental fishes that were based on different sampling methodologies and fish groups (see references above), and which generally argued for a longitudinal decreasing western/eastern gradient of phylogenetic diversity and species richness, and for a decreasing north-south gradient of functional diversity (Ben Rais Lasram et al., 2009; Coll et al., 2010; Mouillot et al., 2011) (see however (Guidetti et al., 2014) for species richness sampled by visual census). The absence of a west/east decreasing trend we observed further suggests that primary production (or more generally food availability) is possibly not the major factor explaining large scale patterns of species richness $S$ and evenness of demersal fish assemblages sampled by trawling, as previously suggested for $S$ (Gaertner et al., 2007). Effects of cumulative human activities, such as exploitation (notably trawling), but also pollution and habitat degradation, could also impact the diversity of these demersal fish assemblages (Coll et al., 2012). However, the large temporal scale of our analysis highlighted that the diversity of Mediterranean demersal fish assemblages has remained stable over the last two decades for all indices considered. This suggests that human pressure had probably already impacted the fish diversity prior to the start of the present survey (i.e. 1994). Furthermore, a loss in species richness can occur only if species 
"disappear" (or became rare and are not sampled anymore) without species gain (e.g. resulting from availability in niche space). Such situations imply unusually strong anthropogenic pressure that would involve more than fishing alone (overfishing can indeed lead to the collapse of fish populations, but hardly to their disappearance).

The remarkable species diversity in the Mediterranean basin needs effective management. We have pointed out that the scale of diversity analysis (i.e. GSA, Biogeographical zone, Basin) and measurement ( $\alpha$ - and $\gamma$-diversity) can change our perception of hotspot locations. Spatial patterns of $S$ at regional scale ( $\gamma$-diversity) generally overlapped with those observed at haul scale ( $\alpha$-diversity), but there were some exceptions. The Gulf of Lions had one of the lowest regional $S$ values while $S$ per haul was one of the highest (suggesting a lower species turnover in this area, i.e. $\beta$-diversity). Conversely, the Strait of Sicily, Algeria and the Tyrrhenian Sea presented relatively low species richness at the haul scale ( $\alpha$-diversity), but relatively high rarefied species richness at the regional scale $(\gamma$-diversity). This underlines the importance of the choice of scales for practical delimitation of priority zones for protection when dealing with assemblage diversity (Devictor et al., 2010).

In conclusion, our study provides a snapshot of the state of the spatio-temporal patterns of demersal fish diversity assessed by complementary diversity components and based on a large standardized data set from scientific trawl samplings. It confirms the importance of considering complementary indices in species diversity assessment, showing that the location of diversity hotspots differs according to species richness or evenness components, and the spatial scale of investigation. We also show that the widely computed Rao's quadratic entropy is not always useful for directly comparing taxonomic, phylogenetic and functional diversity, 
their patterns being linked to the evenness component (Pavoine et al., 2013). This points to research perspectives to develop original diversity indices. Finally, our analysis represents a preliminary step towards studies focused on the drivers of demersal fish diversity in the Mediterranean Sea by revealing a high spatial differentiation of species richness, and stability of evenness and divergence indices across this area. Identifying more explicitly the biotic factors (such as species aggregation, competition or dispersal limitations, e.g. (Boulangeat et al., 2012; Cavieres et al., 2014; Loreau and Mouquet, 1999)), and abiotic factors (such as environmental variables as well as anthropogenic pressure, e.g. (Coll et al., 2012)), in species diversity habitat models would extend our findings within the frame of complementary work dedicated to this aspect. However, a more precise investigation of the effects of these factors requires data availability (e.g. species interactions, fishing effort from Vessel Monitoring System (VMS) data) as well as specific modelling analyses that will need to be performed in forthcoming studies.

\section{Acknowledgments}

We thank two anonymous reviewers for their constructive comments on the manuscript. V.G. is supported by a Presidency $\mathrm{PhD}$ grant of University Montpellier 2. This study was carried out within the framework of the "Species assemblages and biodiversity" working group of the International MEDITS program. We thank colleagues who have participated to the MEDITS trawl surveys since 1994. The manuscript has been proof-read and corrected for the English by Michael Paul.

\section{References}


Albouy, C., Guilhaumon, F., Villéger, S., Mouchet, M., Mercier, L., Culioli, J., Tomasini, J., Le Loch, F., Mouillot, D., 2011. Predicting trophic guild and diet overlap from functional traits: statistics, opportunities and limitations for marine ecology. Mar. Ecol. Prog. Ser. 436, 17-28.

Begon, M., Harper, J.L., Townsend, C.R., 2006. Ecology: Individuals, Populations and Communities, in: Blackwell Science. p. 738.

Ben Rais Lasram, F., Guilhaumon, F., Albouy, C., Somot, S., Thuiller, W., Mouillot, D., 2010. The Mediterranean Sea as a "cul-de-sac" for endemic fishes facing climate change. Glob. Chang. Biol. 16, 3233-3245.

Ben Rais Lasram, F., Guilhaumon, F., Mouillot, D., 2009. Fish diversity patterns in the Mediterranean Sea: deviations from a mid-domain model. Mar. Ecol. Prog. Ser. 376, 253-267.

Bertrand, J., De Sola, L., Papaconstantinou, C., Relini, G., Souplet, A., 2002. The general specifications of the MEDITS surveys. Sci. Mar. 66, 9-17.

Boulangeat, I., Gravel, D., Thuiller, W., 2012. Accounting for dispersal and biotic interactions to disentangle the drivers of species distributions and their abundances. Ecol. Lett. 15, 584-593.

Breiman, L., Friedman, J.H., Olshen, R.A., Stone, C.J., 1984. Classification and Regression Trees, The Wadsworth statisticsprobability series.

Cadotte, M.W., Cavender-Bares, J., Tilman, D., Oakley, T.H., 2009. Using Phylogenetic, Functional and Trait Diversity to Understand Patterns of Plant Community Productivity. PLoS One 4, e5695.

Cadotte, M.W., Jonathan Davies, T., Regetz, J., Kembel, S.W., Cleland, E., Oakley, T.H., 2010. Phylogenetic diversity metrics for ecological communities: integrating species richness, abundance and evolutionary history. Ecol. Lett. 13, 96-105.

Cavieres, L.A., Brooker, R.W., Butterfield, B.J., Cook, B.J., Kikvidze, Z., Lortie, C.J., Michalet, R., Pugnaire, F.I., Schöb, C., Xiao, S., Anthelme, F., Björk, R.G., Dickinson, K.J.M., Cranston, B.H., Gavilan, R., Gutiérrez-Giron, A., Kanka, R., Maalouf, J.P., Mark, A.F., Noroozi, J., Parajuli, R., Phoenix, G.K., Reid, A.M., Ridenour, W.M., Rixen, C., Wipf, S., Zhao, L., Escudero, A., Zaitchik, B.F., Lingua, E., Aschehoug, E.T., Callaway, R.M., 2014. Facilitative plant interactions and climate simultaneously drive alpine plant diversity. Ecol. Lett.

Coll, M., Piroddi, C., Albouy, C., Ben Rais Lasram, F., Cheung, W.W.L., Christensen, V., Karpouzi, V.S., Guilhaumon, F., Mouillot, D., Paleczny, M., Palomares, M.L., Steenbeek, J., Trujillo, P., Watson, R., Pauly, D., 2012. The Mediterranean Sea under siege: spatial overlap between marine biodiversity, cumulative threats and marine reserves. Glob. Ecol. Biogeogr. 21, 465-480. 
Coll, M., Piroddi, C., Steenbeek, J., Kaschner, K., Ben Rais Lasram, F., Aguzzi, J., Ballesteros, E., Bianchi, C.N., Corbera, J., Dailianis, T., Danovaro, R., Estrada, M., Froglia, C., Galil, B.S., Gasol, J.M., Gertwagen, R., Gil, J., Guilhaumon, F., KesnerReyes, K., Kitsos, M.-S., Koukouras, A., Lampadariou, N., Laxamana, E., López-Fé de la Cuadra, C.M., Lotze, H.K., Martin, D., Mouillot, D., Oro, D., Raicevich, S., RiusBarile, J., Saiz-Salinas, J.I., San Vicente, C., Somot, S., Templado, J., Turon, X., Vafidis, D., Villanueva, R., Voultsiadou, E., 2010. The Biodiversity of the Mediterranean Sea: Estimates, Patterns, and Threats. PLoS One 5, e11842.

Crozier, R., Dunnett, L., Agapow, P., 2005. Phylogenetic biodiversity assessment based on systematic nomenclature. Evol. Bioinform. Online 1, 11-36.

D’agata, S., Mouillot, D., Kulbicki, M., Andréfouët, S., Bellwood, D.R., Cinner, J.E., Cowman, P.F., Kronen, M., Pinca, S., Vigliola, L., 2014. Human-Mediated Loss of Phylogenetic and Functional Diversity in Coral Reef Fishes. Curr. Biol. 24, 555-560.

Devictor, V., Mouillot, D., Meynard, C., Jiguet, F., Thuiller, W., Mouquet, N., 2010. Spatial mismatch and congruence between taxonomic, phylogenetic and functional diversity: the need for integrative conservation strategies in a changing world. Ecol. Lett. 13, 10301040 .

Froese, R., Pauly., D., 2011. FishBase. URL www.fishbase.org

Gaertner, J., Bertrand, J., Relini, G., Papaconstantinou, C., Mazouni, N., De Sola, L., Durbec, J., Jukic-Peladic, S., Souplet, A., 2007. Spatial pattern in species richness of demersal fish assemblages on the continental shelf of the northern Mediterranean Sea: a multiscale analysis. Mar. Ecol. Prog. Ser. 341, 191-203.

Gaertner, J.-C., Maiorano, P., Mérigot, B., Colloca, F., Politou, C.-Y., Gil De Sola, L., Bertrand, J. a, Murenu, M., Durbec, J.-P., Kallianiotis, A., Mannini, A., 2013. LargeScale Diversity of Slope Fishes: Pattern Inconsistency between Multiple Diversity Indices. PLoS One 8, e66753.

Gaertner, J.-C., Mérigot, B., Rélini, G., Bertrand, J.A., Mazouni, N., Politou, C.-Y., Gil De Sola, L., Kallianiotis, A., Carpentieri, P., Murenu, M., Durbec, J.-P., Vrgoc, N., Ungaro, N., 2010. Reproducibility of the multi-component aspect of species diversity across different areas and scales: towards the constitution of a shortlist of complementary indices for monitoring fish diversity? Ecography (Cop.). 33, 1123-1135.

GFCM, 2012. Report of the fourteenth session of the Scientific Advisory Committee. Sofia, Bulgaria: FAO Fisheries and Aquaculture.

Gower, J.C., 1971. A General Coefficient of Similarity and Some of Its Properties. Biometrics 27, 857-871.

Guidetti, P., Baiata, P., Ballesteros, E., Di Franco, A., Hereu, B., Macpherson, E., Micheli, F., Pais, A., Panzalis, P., Rosenberg, A. a, Zabala, M., Sala, E., 2014. Large-scale 
assessment of Mediterranean marine protected areas effects on fish assemblages. PLoS One 9, e91841.

Halpern, B.S., Walbridge, S., Selkoe, K.A., Kappel, C. V, Micheli, F., D’Agrosa, C., Bruno, J.F., Casey, K.S., Ebert, C., Fox, H.E., Fujita, R., Heinemann, D., Lenihan, H.S., Madin, E.M.P., Perry, M.T., Selig, E.R., Spalding, M., Steneck, R., Watson, R., 2008. A Global Map of Human Impact on Marine Ecosystems. Science. 319, 948-952.

Izsak, Papp, 2000. A link between ecological diversity indices and measures of biodiversity. Ecol. Modell. 130, 151-156.

Jost, L., 2006. Entropy and diversity. Oikos 113, 363-375.

Kelly, S., Grenyer, R., Scotland, R.W., 2014. Phylogenetic trees do not reliably predict feature diversity. Divers. Distrib. in press.

Lande, R., 1996. Statistics and partitioning of species diversity, and similarity among multiple communities. Oikos 76, 5-13.

Lefcheck, J.S., Buchheister, A., Laumann, K.M., Stratton, M.A., Sobocinski, K.L., Chak, S.T.C., Clardy, T.R., Reynolds, P.L., Latour, R.J., Duffy, J.E., 2014. Dimensions of biodiversity in Chesapeake Bay demersal fishes: patterns and drivers through space and time. Ecosphere 5, 14.

Loreau, M., Mouquet, N., 1999. Immigration and the Maintenance of Local Species Diversity. Am. Nat. 154, 427-440.

Mason, N., Mouillot, D., Lee, W., Wilson, J., 2005. Functional richness, functional evenness and functional divergence: the primary components of functional diversity. Oikos 111, $112-118$.

McCullagh, P., Nelder, J.A., 1989. Generalized Linear Models, Second Edition, Generalized Linear Models Second Edition.

McGill, B.J., Enquist, B.J., Weiher, E., Westoby, M., 2006. Rebuilding community ecology from functional traits. Trends Ecol. Evol. 21, 178-185.

Mérigot, B., Bertrand, J.A., Gaertner, J.J.-C., Durbec, J.-P., Mazouni, N., Manté, C., 2007. Multi-component structuration of the species diversity of groundfish assemblages of the east coast of Corsica (Mediterranean Sea): variation according to the bathymetric. Fish. Res. 88, 120-132.

Mérigot, B., Durbec, J.-P., Gaertner, J.-C., 2010. On goodness-of-fit measure for dendrogrambased analyses. Ecology 91, 1850-1859.

Meynard, C.N., Devictor, V., Mouillot, D., Thuiller, W., Jiguet, F., Mouquet, N., 2011. Beyond taxonomic diversity patterns: how do $\alpha, \beta$ and $\gamma$ components of bird functional 
and phylogenetic diversity respond to environmental gradients across France? Glob. Ecol. Biogeogr. 20, 893-903.

Meynard, C.N., Mouillot, D., Mouquet, N., Douzery, E.J.P., 2012. A Phylogenetic Perspective on the Evolution of Mediterranean Teleost Fishes. PLoS One 7, e36443.

Mouillot, D., Albouy, C., Guilhaumon, F., Ben Rais Lasram, F., Coll, M., Devictor, V., Meynard, C.N., Pauly, D., Tomasini, J.A., Troussellier, M., Velez, L., Watson, R., Douzery, E.J.P., Mouquet, N., 2011. Protected and threatened components of fish biodiversity in the Mediterranean sea. Curr. Biol. 21, 1044-1050.

Pavoine, S., 2012. Clarifying and developing analyses of biodiversity: towards a generalisation of current approaches. Methods Ecol. Evol. 3, 509-518.

Pavoine, S., Gasc, A., Bonsall, M.B., Mason, N.W.H., 2013. Correlations between phylogenetic and functional diversity: mathematical artefacts or true ecological and evolutionary processes? J. Veg. Sci. 24, 781-793.

Petchey, O.L., Gaston, K.J., 2002. Functional diversity (FD), species richness and community composition. Ecol. Lett. 5, 402-411.

Pinheiro, J.C., Bates, D.M., 2000. Mixed-Effects Models in S and S-PLUS, Statistics and Computing.

R Core Team, 2013. R: A language and environment for statistical computing. R Foundation for Statistical Computing, Vienna, Austria. R A Lang. Environ. Stat. Comput.

Rao, C., 1982. Diversity and dissimilarity coefficients: a unified approach. Theor. Popul. Biol. $43,24-43$.

Ricotta, C., Bacaro, G., Marignani, M., Godefroid, S., Mazzoleni, S., 2012. Computing diversity from dated phylogenies and taxonomic hierarchies: does it make a difference to the conclusions? Oecologia.

Rochet, M.-J., Trenkel, V.M., Carpentier, A., Coppin, F., De Sola, L.G., Léauté, J.-P., Mahé, J.-C., Maiorano, P., Mannini, A., Murenu, M., Piet, G., Politou, C.-Y., Reale, B., Spedicato, M.-T., Tserpes, G., Bertrand, J. a., 2010. Do changes in environmental and fishing pressures impact marine communities? An empirical assessment. J. Appl. Ecol. 47, 741-750.

Schleuter, D., Daufresne, M., Massol, F., Argillier, C., 2010. A user's guide to functional diversity indices. Ecol. Monogr.

Schmera, D., Erős, T., Podani, J., 2007. A measure for assessing functional diversity in ecological communities. Aquat. Ecol. 43, 157-167.

Simpson, E.H., 1949. Measurement of Diversity. Nature 163, 688-688. 
Smith, B., Wilson, J.B., 1996. Oikos s guide to evenness indices. Oikos 76, 70-82.

Stuart-Smith, R.D., Bates, A.E., Lefcheck, J.S., Duffy, J.E., Baker, S.C., Thomson, R.J., Stuart-Smith, J.F., Hill, N. a., Kininmonth, S.J., Airoldi, L., Becerro, M. a., Campbell, S.J., Dawson, T.P., Navarrete, S. a., Soler, G. a., Strain, E.M. a., Willis, T.J., Edgar, G.J., 2013. Integrating abundance and functional traits reveals new global hotspots of fish diversity. Nature 501, 539-542.

Thuiller, W., Lavergne, S., Roquet, C., Boulangeat, I., Lafourcade, B., Araujo, M.B., 2011. Consequences of climate change on the tree of life in Europe. Nature 470, 531-534.

Villéger, S., Mason, N., Mouillot, D., 2008. New multidimensional functional diversity indices for a multifaceted framework in functional ecology. Ecology 89, 2290-301.

Villéger, S., Miranda, J.R., Hernández, D.F., Mouillot, D., 2010. Contrasting changes in taxonomic vs. functional diversity of tropical fish communities after habitat degradation. Ecol. Appl. 20, 1512-1522.

Webb, C.O., Ackerly, D.D., McPeek, M.A., Donoghue, M.J., 2002. Phylogenies and community ecology. Annu. Rev. Ecol. Syst. 33, 475-505.

Whittaker, R.H., 1972. Evolution and measurement of species diversity. Taxon 21, 213-251. 


\section{Tables}

Table 1. Generalized linear model (GLM) investigating spatio-temporal variability of species richness $S$ and functional divergence $F D$.

\begin{tabular}{llllll}
\hline & & Total & GSA & Year & GSA : Year \\
\hline S & $\alpha$-diversity & $18,85 \%$ & $10,52 \%(17)$ & $1,76 \%(18)$ & $6,65 \%(229)$ \\
& $\gamma$-diversity & $76,81 \%$ & $70,61 \%(16)^{\mathrm{a}}$ & $6,2 \%(18)$ & $\mathrm{b}$ \\
\multirow{3}{*}{$1-F D$} & $\alpha$-diversity & $7 \%$ & $2.4 \%(17)$ & $<1 \%(18)$ & $4 \%$ \\
& $\gamma$-diversity & $10.47 \%$ & $4.72 \%(17)$ & $5.75 \%(18)$ & $\mathrm{b}$ \\
\hline
\end{tabular}

Indices measured per haul (i.e. $\alpha$-diversity) and per GSA (i.e. $\gamma$-diversity) on 19,886 hauls for 19 years in 18 geographical sub-areas (GSA) of the Mediterranean Sea. GLM including both Year and GSA as explicative factors, with a Normal and Gamma error distributions were considered for $S$ and 1-FD respectively, with an identity link in both cases. Percentages represent the part of deviance explained by each variable in the same model, with degrees of freedom in brackets. All effects are significant (p $<0.05$ ). Note that $S$ computed per GSA was rarefied to 25 hauls (see Materials and methods section).

${ }^{\text {a }}$ Due to the rarefaction method, GSA 8 is excluded from the analysis, the total number of hauls being below 25 for each year in this GSA.

${ }^{\mathrm{b}}$ Models for $S$ and $1-F D$ per GSA do not include interaction, as one value per GSA and per year is available. 


\section{Figures}

1 Northern Alboran Sea

4 Algeria

5 Balearic Islands

6 Northern Spain

7 Gulf of Lions

8 Corsica
9 Ligurian, Northern Tyrrhenian Sea 10 Southern Tyrrhenian Sea

11 Sardinia

15 Malta

16 Strait of Sicily

17 Northern Adriatic Sea
18 Southern Adriatic Sea

19 North-Western Ionian Sea

20 Eastern Ionian Sea

22 Aegean Sea

23 Cretan Sea

25 Cyprus

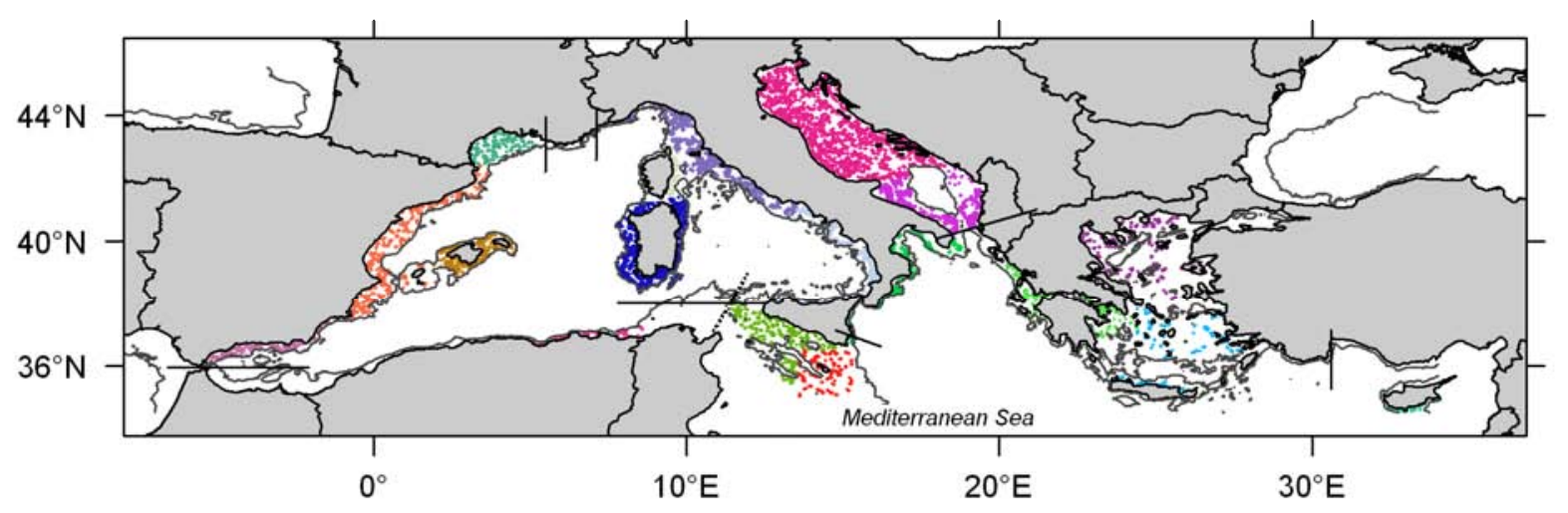

Fig. 1. Study area and sampling sites. Study area of trawl surveys based on the MEDITS program protocol with the position of 19,886 hauls sampled between 1994 and 2012 in 18 geographical sub-areas GSAs; each color corresponds to one of the 18 Geographical SubAreas (GSA) defined by the General Fisheries Commission for the Mediterranean (www.gfcm.org). The grey line represents the sampling limit of $800 \mathrm{~m}$ depth. The spatial boundaries of the 7 biogeographical zones (Iberian-Lions, Tyrrhenian, Algerian-Maltese, Ionian, Adriatic, Aegean, and Cypriot) are delimited by thick black lines. The thick black dotted line represents the spatial boundary between eastern and western basins. 


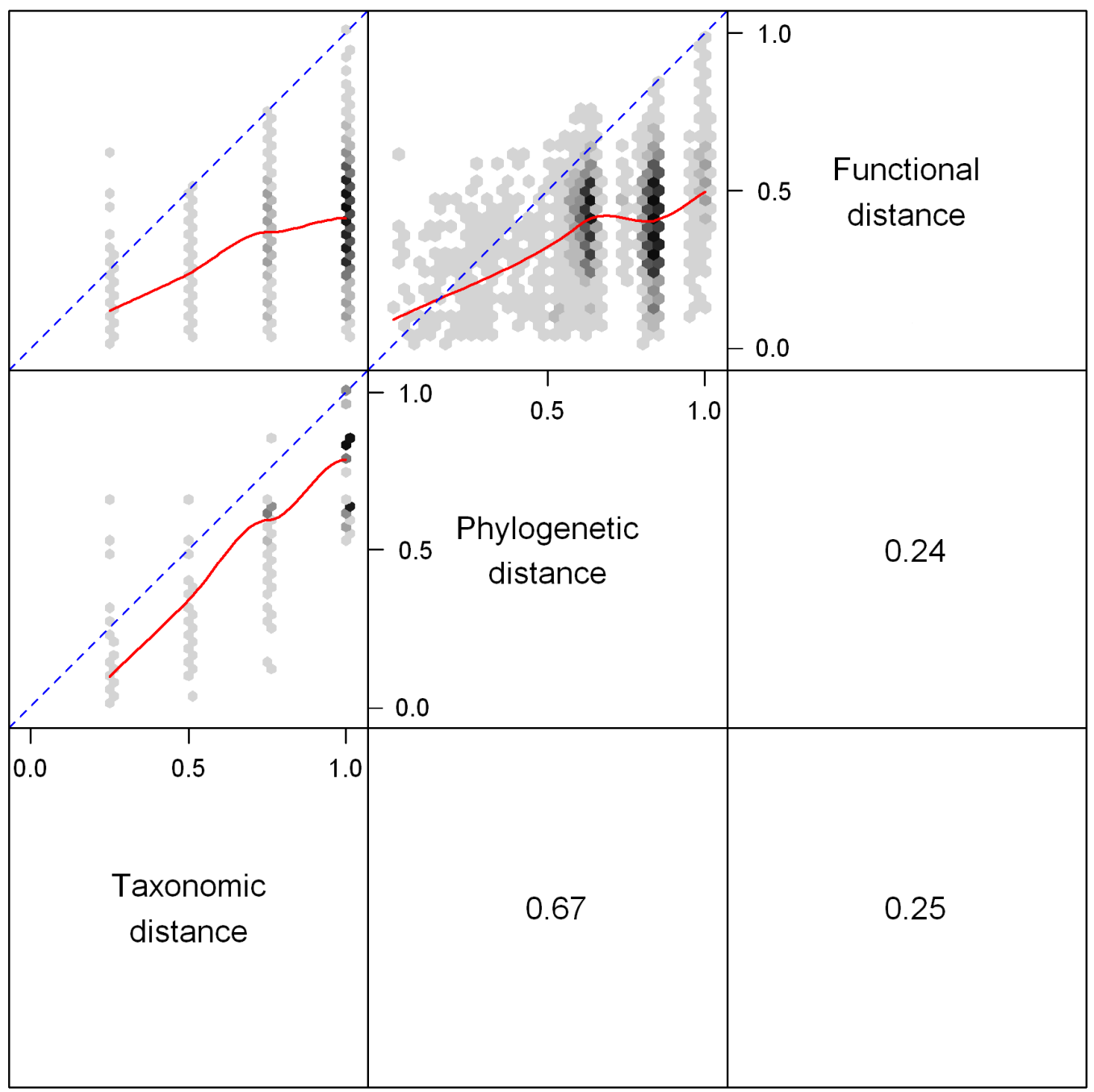

Fig. 2. Matrix plots between phylogenetic, taxonomic and functional species distance matrices of 134 osteichtyes fish species. In the upper panel, each point represents a species' pairwise distances according to two diversity components. If a species is considered equally distant for both components, then the point is placed on the first bisector (i.e. $\mathrm{y}=\mathrm{x}$ ) representing the situation for which both matrices are identical (i.e. have the same values). The continuous line represents a local weighted regression ("loess"). The Pearson correlation coefficient is represented in the lower panel. 


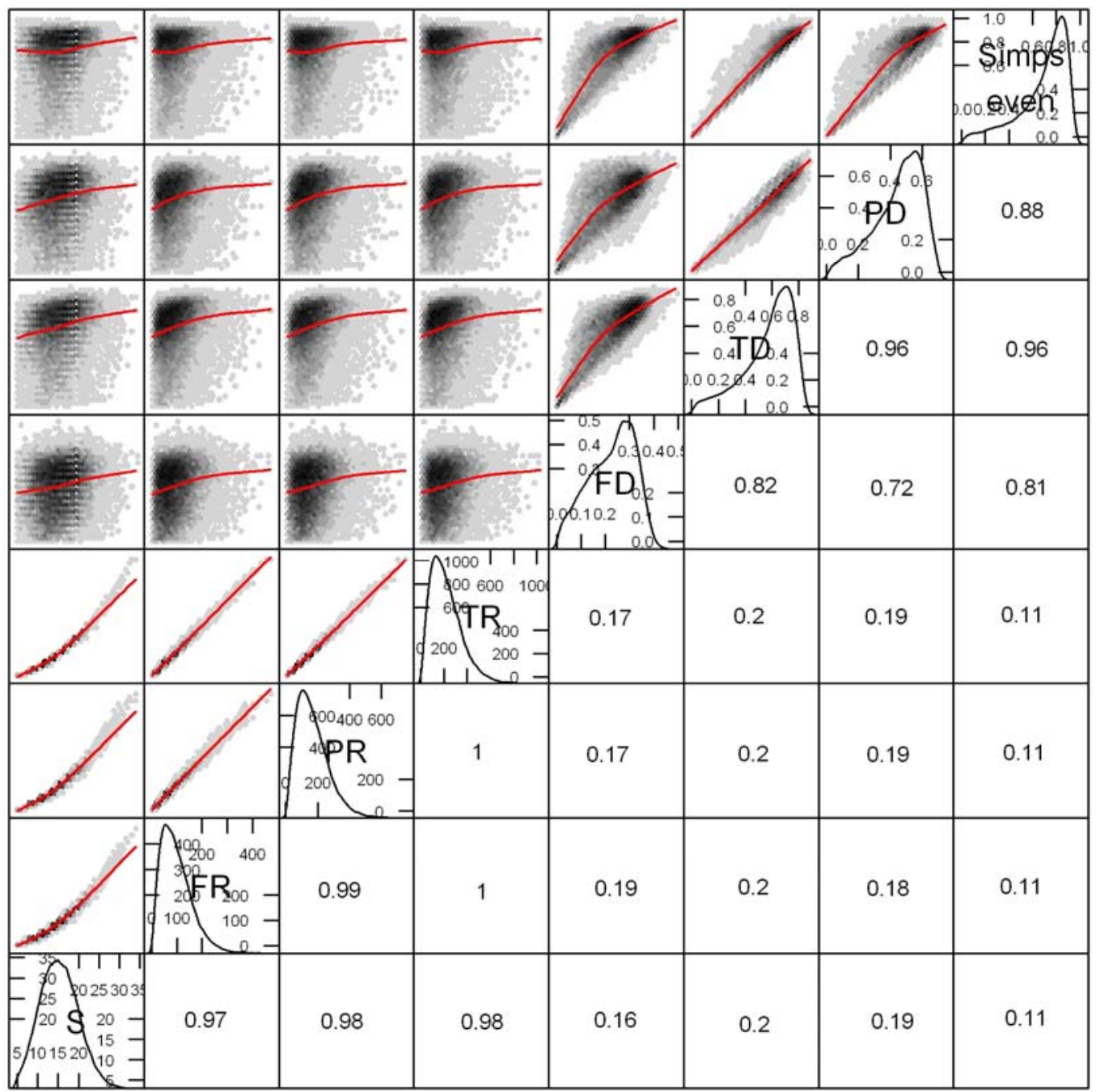

Fig. 3. Draftsman's plot of diversity indices computed on 19,886 hauls. In the upper panel, the pairwise relationship, the continuous line representing a local weighted regression ("loess"). The Pearson correlation coefficient is represented in the lower panel, and the marginal distribution for each index in the diagonal. $S$ is species richness; $T D / P D / F D$ are taxonomic, phylogenetic, functional divergences respectively, computed by Rao's quadratic entropy $Q$ on fish abundance data; Simps even is Simpson evenness; $T R / P R / F R$ are taxonomic, phylogenetic and functional richness, computed by the modified Rao's quadratic entropy $Q+$ on fish presence/absence data. 
GSA

$7,17,18,25$

$73.2 \pm 7.7$ species; 61 obs; $6.7 \%$

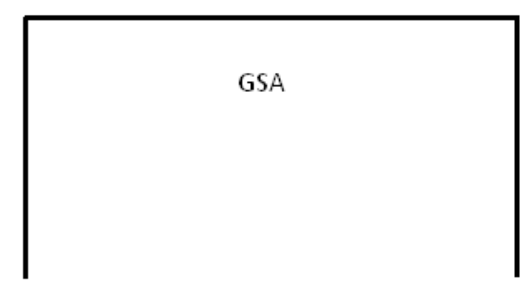

17

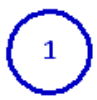

$65.8 \pm 5.5$ species 18 obs
$7,18,25$

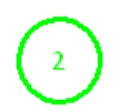

$76.3 \pm 6.4$ species $97.8 \pm 5.4$ species

43 obs 24 obs
$1,4,5,6,9,10,11,15,16,19,20,22,23$

$87.6 \pm 6.6$ species; 184 obs; $14.1 \%$

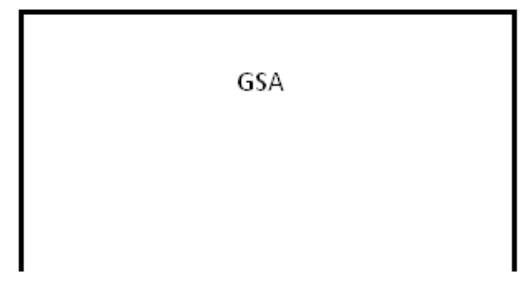

$1,4,6,9,10,11,15,16,19,20,22,23$

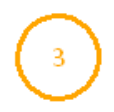

$85.9 \pm 5.1$ species 160 obs

b)

$17.35 ; 19886$ hauls; $9.2 \%$

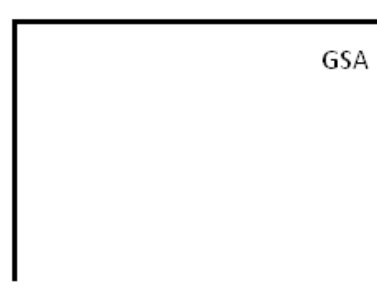

$4,9,10,11,16,17,18,19,23,25$

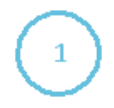

$16.3 \pm 4.8$ species 13733 hauls
$1,5,6,7,8,15,20,22$

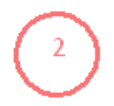

$19.7 \pm 5.3$ species 6153 hauls

Fig. 4. Regression tree models for fish species richness $S$. Values computed (a) per haul (i.e. $\alpha$ diversity), and (b) per GSA (i.e. $\gamma$ - diversity) across the Mediterranean Sea. The splitting variable (Geographical Sub Area GSA and Year) and its modalities value (see Fig. 1) are shown on each branch (horizontal lines). The terminal nodes show the $S$ mean values and 
associated standard deviations, number of observations (obs, i.e. rarefied $S$ values) per node and hauls from which the mean values have been computed for $\gamma$ and $\alpha$-diversity, respectively. Note that due to the rarefaction method, GSA8 is excluded from the per GSA analysis (i.e. $\gamma$-diversity), the total number of hauls of being below 25 for each in this GSA. 
a)

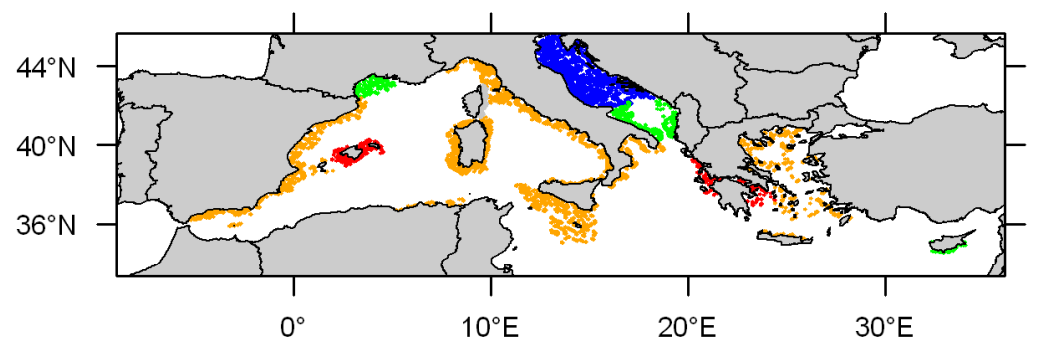

65.8 (5.5) species 76.3 (6.4) species 85.9 (5.1) species 97.8 (5.4) species

b) $\quad \mathrm{Y}$-diversity $(65.9 \%$ of explained variance)

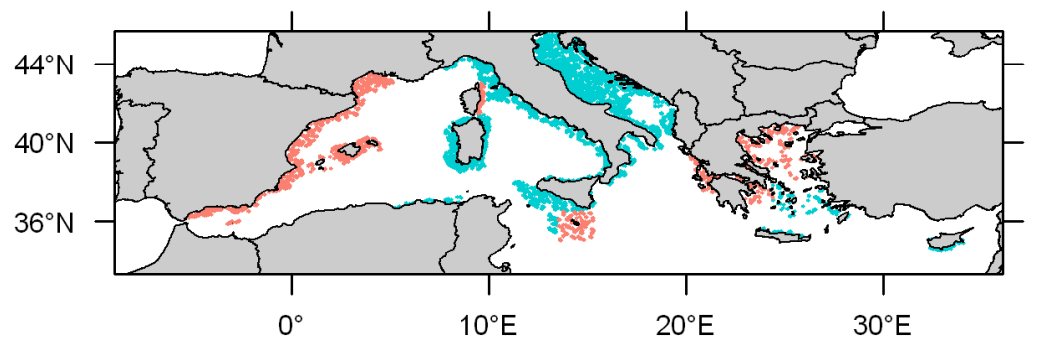

19.7 (5.3) species $16.3(4.8)$ species

Fig. 5. Map of spatial partitioning of fish species richness $S$ resulting from regression tree models. Values computed (a) per haul (i.e. $\alpha$-diversity), and (b) per GSA (i.e. $\gamma$-diversity) according the regression tree models (see Fig. 4) implemented for 19 years and 18 Geographical Sub Areas (GSAs) in the Mediterranean Sea. Note that due to the rarefaction method, GSA8 is excluded from the per GSA analysis (i.e. $\gamma$-diversity), the total number of hauls of being below 25 for each in this GSA. Values represent $S$ mean values and associated standard deviation. 


\section{Appendices}

\section{Appendix A. List of species included in the study}

Acantholabrus palloni

Alepocephalus rostratus

Anthias anthias

Aphia minuta

Argentina sphyraena

Argentina spp

Argyropelecus hemigymnus

Arnoglossus imperialis

Arnoglossus laterna

Arnoglossus rueppelii

Arnoglossus thori

Aulopus filamentosus

Bathypterois dubius

Bathysolea profundicola

Bellottia apoda

Benthocometes robustus

Benthosema glaciale

Blennius ocellaris

Boops boops

Bothus podas

Buglossidium luteum

Callionymus lyra

Callionymus maculatus
Risso, 1810

Risso, 1820

Linnaeus, 1758

Risso, 1810

Linnaeus, 1758

Cocco, 1829

Rafinesque, 1810

Walbaum, 1792

Cocco, 1844

Kyle, 1913

Bloch, 1792

Vaillant, 1888

Vaillant, 1888

Giglioli, 1883

Goode \& Bean, 1886

Reinhardt, 1837

Linnaeus, 1758

Linnaeus, 1758

Delaroche, 1809

Risso, 1810

Linnaeus, 1758

Rafinesque, 1810 
Callionymus risso

Capros aper

Carapus acus

Cataetyx alleni

Centracanthus cirrus

Centrolophus niger

Centrophorus granulosus

Centrophorus uyato

Cepola macrophthalma

Ceratoscopelus maderensis

Chauliodus sloani

Chelidonichthys cuculus

Chelidonichthys lucerna

Chelidonichthys obscurus

Chimaera monstrosa

Chlorophthalmus agassizi

Citharus linguatula

Coelorinchus caelorhincus

Dalatias licha

Dasyatis pastinaca

Deltentosteus quadrimaculatus

Dentex dentex

Diaphus holti

Diaphus rafinesquii

Dicologlossa hexophthalma

Diplodus annularis
Lesueur, 1814

Linnaeus, 1758

Brünnich, 1768

Byrne, 1906

Rafinesque, 1810

Gmelin, 1789

Bloch \& Schneider, 1801

Rafinesque, 1810

Linnaeus, 1758

Lowe, 1839

Bloch \& Schneider, 1801

Linnaeus, 1758

Linnaeus, 1758

Walbaum, 1792

Linnaeus, 1758

Bonaparte, 1840

Linnaeus, 1758

Risso, 1810

Bonnaterre, 1788

Linnaeus, 1758

Valenciennes, 1837

Linnaeus, 1758

Tåning, 1918

Cocco, 1838

Bennett, 1831

Linnaeus, 1758 
Diplodus vulgaris

Dipturus oxyrinchus

Dysomma brevirostre

Echinorhinus brucus

Echiodon dentatus

Engraulis encrasicolus

Epigonus constanciae

Epigonus denticulatus

Epigonus telescopus

Epinephelus aeneus

Etmopterus spinax

Eutelichthys leptochirus

Eutrigla gurnardus

Gadella maraldi

Gadiculus argenteus

Gaidropsarus biscayensis

Gaidropsarus mediterraneus

Galeorhinus galeus

Galeus atlanticus

Galeus melastomus

Glossanodon leioglossus

Gnathophis mystax

Gobius niger

Gonostoma denudatum

Gymnura altavela

Helicolenus dactylopterus
Geoffroy Saint-Hilaire, 1817

Linnaeus, 1758

Facciolà, 1887

Bonnaterre, 1788

Cuvier, 1829

Linnaeus, 1758

Giglioli, 1880

Dieuzeide, 1950

Risso, 1810

Geoffroy Saint-Hilaire, 1817

Linnaeus, 1758

Tortonese, 1959

Linnaeus, 1758

Risso, 1810

Guichenot, 1850

Collett, 1890

Linnaeus, 1758

Linnaeus, 1758

Vaillant, 1888

Rafinesque, 1810

Valenciennes, 1848

Delaroche, 1809

Linnaeus, 1758

Rafinesque, 1810

Linnaeus, 1758

Delaroche, 1809 
Heptranchias perlo

Hexanchus griseus

Hoplostethus mediterraneus mediterraneus

Hygophum benoit

Hygophum hygomii

Hymenocephalus italicus

Labrus viridis

Lampanyctus crocodilus

Lepidopus caudatus

Lepidorhombus boscii

Lepidorhombus whiffiagonis

Lepidotrigla cavillone

Lepidotrigla dieuzeidei

Lesueurigobius friesii

Lesueurigobius sanzi

Lesueurigobius suerii

Leucoraja circularis

Leucoraja fullonica

Leucoraja melitensis

Leucoraja naevus

Lithognathus mormyrus

Lobianchia dofleini

Lophius spp.

Macroramphosus scolopax

Maurolicus muelleri

Merluccius merluccius
Bonnaterre, 1788

Bonnaterre, 1788

Cuvier, 1829

Cocco, 1838

Lütken, 1892

Giglioli, 1884

Linnaeus, 1758

Risso, 1810

Euphrasen, 1788

Risso, 1810

Walbaum, 1792

Lacepède, 1801

Blanc \& Hureau, 1973

Malm, 1874

De Buen, 1918

Risso, 1810

Couch, 1836

Linnaeus, 1758

Clarck, 1926

Müller \& Henle, 1841

Linnaeus, 1758

Zugmayer, 1911

Linnaeus, 1758

Linnaeus, 1758

Gmelin, 1789

Linnaeus, 1758 
Microchirus ocellatus

Microchirus variegatus

Micromesistius poutassou

Molva dypterygia

Molva molva

Monochirus hispidus

Mora moro

Mullus barbatus barbatus

Mustelus asterias

Mustelus mustelus

Myctophum punctatum

Nettastoma melanurum

Nezumia sclerorhynchus

Notoscopelus bolini

Notoscopelus elongatus

Oxynotus centrina

Pagellus acarne

Pagellus bellottii

Pagellus bogaraveo

Pagellus erythrinus

Pagrus pagrus

Paralepis coregonoides

Pegusa impar

Pegusa lascaris

Peristedion cataphractum

Phycis blennoides
Linnaeus, 1758

Donovan, 1808

Risso, 1826

Pennant, 1784

Linnaeus, 1758

Rafinesque, 1814

Risso, 1810

Linnaeus, 1758

Cloquet, 1821

Linnaeus, 1758

Rafinesque, 1810

Rafinesque, 1810

Valenciennes, 1838

Nafpaktitis, 1975

Costa, 1844

Linnaeus, 1758

Risso, 1827

Steindachner, 1882

Brünnich, 1768

Linnaeus, 1758

Linnaeus, 1758

Risso, 1820

Bennett, 1831

Risso, 1810

Linnaeus, 1758

Brünnich, 1768 
Physiculus dalwigki

Platichthys flesus

Polyprion americanus

Pomatoschistus marmoratus

Raja asterias

Raja brachyura

Raja clavata

Raja miraletus

Raja montagui

Raja polystigma

Raja undulata

Rostroraja alba

Schedophilus ovalis

Scophthalmus maximus

Scophthalmus rhombus

Scorpaena elongata

Scorpaena loppei

Scorpaena notata

Scorpaena porcus

Scorpaena scrofa

Scyliorhinus canicula

Scyliorhinus stellaris

Serranus cabrilla

Serranus hepatus

Solea senegalensis

Solea solea
Kaup, 1858

Linnaeus, 1758

Bloch \& Schneider, 1801

Risso, 1810

Delaroche, 1809

Lafont, 1873

Linnaeus, 1758

Linnaeus, 1758

Fowler, 1910

Regan, 1923

Lacepède, 1802

Lacepède, 1802

Cuvier, 1833

Linnaeus, 1758

Linnaeus, 1758

Cadenat, 1943

Cadenat, 1943

Rafinesque, 1810

Linnaeus, 1758

Linnaeus, 1758

Linnaeus, 1758

Linnaeus, 1758

Linnaeus, 1758

Linnaeus, 1758

Kaup, 1858

Linnaeus, 1758 
Spicara maena

Spicara smaris

Spondyliosoma cantharus

Squalus acanthias

Squalus blainville

Squatina aculeata

Squatina oculata

Squatina squatina

Stomias boa boa

Symbolophorus veranyi

Symphurus ligulatus

Symphurus nigrescens

Synapturichthys kleinii

Synchiropus phaeton

Synodus saurus

Torpedo marmorata

Torpedo nobiliana

Torpedo torpedo

Trachinus araneus

Trachinus draco

Trachinus radiatus

Trachurus mediterraneus

Trachurus picturatus

Trachurus trachurus

Trachyrincus scabrus

Trigla lyra
Linnaeus, 1758

Linnaeus, 1758

Linnaeus, 1758

Linnaeus, 1758

Risso, 1827

Cuvier, 1829

Bonaparte, 1840

Linnaeus, 1758

Risso, 1810

Moreau, 1888

Cocco, 1844

Rafinesque, 1810

Risso, 1827

Günther, 1861

Linnaeus, 1758

Risso, 1810

Bonaparte, 1835

Linnaeus, 1758

Cuvier, 1829

Linnaeus, 1758

Cuvier, 1829

Steindachner, 1868

Bowdich, 1825

Linnaeus, 1758

Rafinesque, 1810

Linnaeus, 1758 
Trigloporus lastoviza

Trisopterus capelanus

Upeneus pori

Uranoscopus scaber

Vinciguerria poweriae

Zenopsis conchifer

Zeus faber
Bonnaterre, 1788

Linnaeus, 1758

Ben-Tuvia \& Golani, 1989

Linnaeus, 1758

Cocco, 1838

Lowe, 1852

Linnaeus, 1758 


\section{Appendix B.}

\section{Part B1. Functional richness, evenness and divergence indices.}

For a given phylogenetic, taxonomic or functional component, there are other approaches to study the richness/evenness/divergence components of diversity by the means of mathematically uncorrelated indices. However, using such an approach for direct comparison between phylogenetic, taxonomic or functional facets from the same index (i.e. mathematical formula), as we did with $Q^{+}$or $Q$, is not necessarily accurate. (Villéger et al., 2008) proposed to measure functional richness, evenness and divergence by three indices related to the functional space built using species functional traits. Primarily designed to monitor functional diversity, this approach does not seem to be appropriate for the phylogenetic and taxonomic components because of the semi-quantitative taxonomic or phylogenetic matrices (for instance, taxonomic pair-wise distances being equal of 0.25/0.5/0.75/1).

Functional diversity investigated on our data within the framework proposed by (Villéger et al., 2008) confirmed the absence of a gradient for all of three functional components, with a spatial GSA structure for functional richness, and a local variability within GSA for functional evenness and divergence at haul measures. The homogenous areas in term of functional richness partially match with those of species richness, confirming high functional richness in the East Ionian, Aegean Sea and Gulf of Lions. 


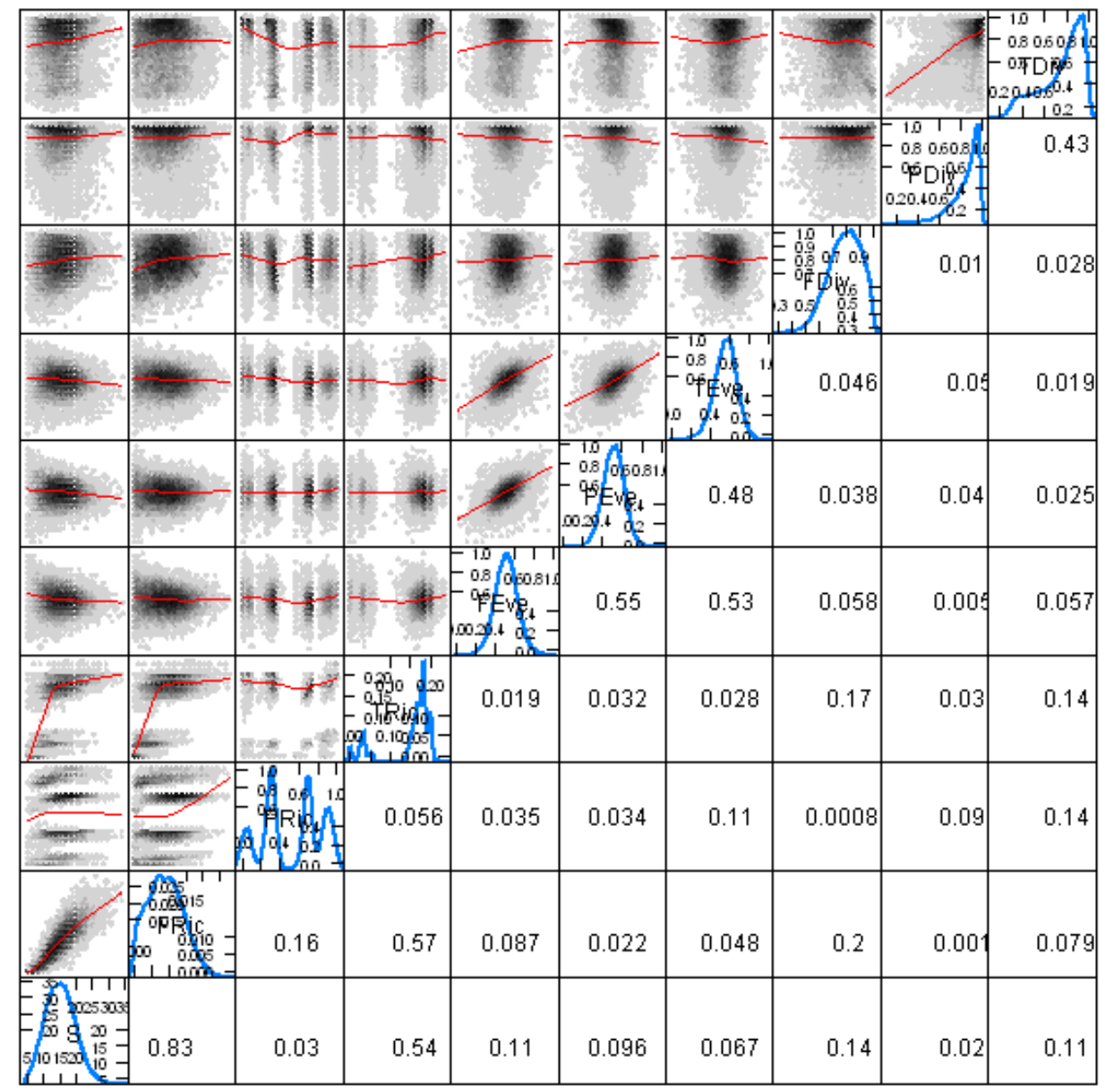

Fig. B1. Draftsman's plot of diversity indices computed for 19,886 hauls on a list of 134 species. The pairwise relationship is in the upper panel, the red line represents a local weighted regression ("loess"), the Spearman rank correlation coefficient in the lower panel, and the marginal distribution for each index in the diagonal. $S$ is species richness; FRic/PRic/TRic are functional, phylogenetic and taxonomic richness; FEve/PEve/TEve are functional, phylogenetic and taxonomic evenness; FDiv/PDiv/TDiv taxonomic, functional divergences distances per sample-haul respectively; indices are computed on a list of 134 species. 
Table B1. Generalized linear model (GLM) investigating spatio-temporal variability of functional richness FRic, functional evenness FEve and functional divergence FDiv measured per haul (i.e. $\alpha$-diversity) and per GSA (i.e. $\gamma$-diversity). Indices computed for 19 years in 18 GSA or 7 biogeographical zones (BGZ) in the Mediterranean Sea. GLM including both year and GSA/BGZ/Basin as explicative factors, with a Normal were considered for all variables. All effects are significant $(\mathrm{p}<0.05)$. Percentages of explained deviance are indicated, with degrees of freedom into brackets.

\begin{tabular}{llllll}
\hline & & Total & GSA & Year & GSA:Year \\
\hline Fric & $\alpha$-diversity & $15,36 \%$ & $8 \%$ & $0,60 \%$ & $6,31 \%$ \\
Feve & $\alpha$-diversity & $8 \%$ & $5,07 \%$ & $0,20 \%$ & $2,71 \%$ \\
1-Fdiv & $\alpha$-diversity & $12,10 \%$ & $8,50 \%$ & $0,80 \%$ & $3,38 \%$ \\
Fric & $\gamma$-diversity & $71,18 \%$ & $66,25 \%$ & $4,94 \%$ & a \\
Feve & $\gamma$-diversity & $41,00 \%$ & $33,80 \%$ & $7,20 \%$ & a \\
1-Fdiv & $\gamma$-diversity & $55,60 \%$ & $49,57 \%$ & $9 \%$ & a
\end{tabular}

\begin{tabular}{|c|c|c|c|c|c|}
\hline & & Total & BGZ & Year & BGZ:Year \\
\hline Fric & $\alpha$-diversity & $8,73 \%$ & $4,70 \%$ & $1,55 \%$ & $3,16 \%$ \\
\hline Feve & $\alpha$-diversity & $5 \%$ & $3,03 \%$ & $0,70 \%$ & $1,20 \%$ \\
\hline 1-Fdiv & $\alpha$-diversity & $5,66 \%$ & $3,50 \%$ & $0,36 \%$ & $1,80 \%$ \\
\hline Fric & $\gamma$-diversity & $29,53 \%$ & $22,67 \%$ & $6,85 \%$ & $\mathrm{a}$ \\
\hline Feve & $\gamma$-diversity & $13,04 \%$ & $5,50 \%$ & $7,54 \%$ & $\mathrm{a}$ \\
\hline 1-Fdiv & $\gamma$-diversity & $39,16 \%$ & $31,80 \%$ & $7,36 \%$ & $\mathrm{a}$ \\
\hline
\end{tabular}

${ }^{a}$ Models for indices values per GSA do not include interaction, as one value per GSA and per year is available. 
FRic)

$0.009 ; 19754$ hauls; $4.4 \%$

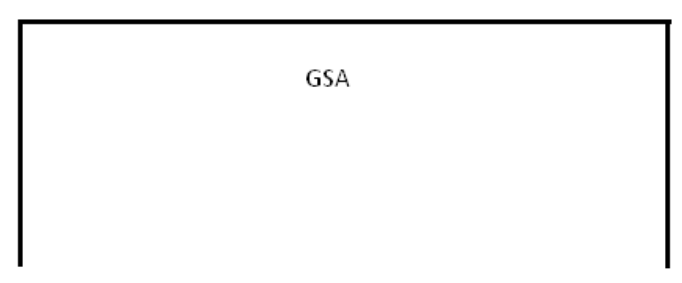

$1,4,5,8,9,19,11,15,16,17,18,19,23,25$

$6,7,20,22$
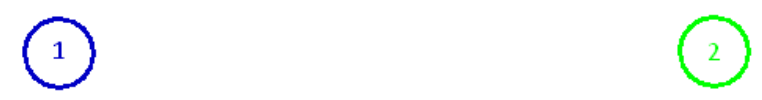

$0.008 \pm 0.004$

15848 hauls

$0.012 \pm 0.005$

3906 hauls

FEve)

$0.522 ; 19754$ hauls; $3.4 \%$

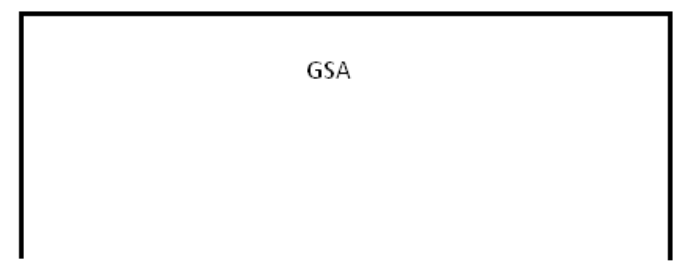

$1,4,5,6,7,8,9,10,11,15,16,20,22,23,25$

$17,18,19$

(1)

$0.51 \pm 0.11$

13955 hauls

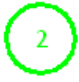

$0.555 \pm 0.11$

5799 hauls

FDiv)

$0.79 ; 19754$ hauls; $6.5 \%$

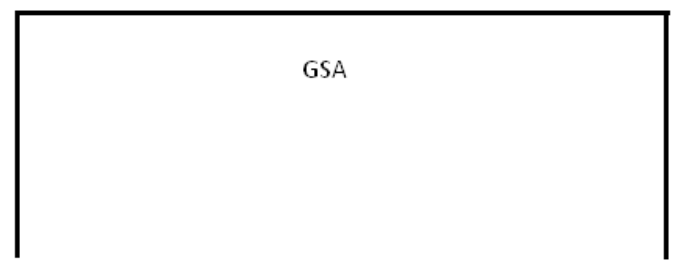

$1,4,6,7,9,10,16,17,18,19$

1999-2012

(1)

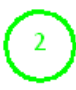

$0.77 \pm 0.11$

14517 hauls

$0.84 \pm 0.12$

5237 hauls 
Fig. B2. Regression trees for fish species richness FRic, FEve and FDiv computed per haul (i.e. $\alpha$-diversity) across the Mediterranean Sea. The splitting variable (GSA and year) and its modalities value are shown on each branch (horizontal lines). The terminal nodes show the FRic, FEve and FDiv mean values, number of hauls from which the mean values have been computed $\alpha$ diversities, respectively.

Part B2. “Effective numbers" for taxonomic, phylogenetic and functional divergences, and Simpson's evenness.

Jost recently promoted the use of indices corresponding to the equivalent number of species that would be in the sample in the case of perfect evenness, i.e. if all individuals are equally distributed among species (Jost, 2006). (Jost, 2006) proposed calling this concept and corresponding indices 'true diversity', also known as "effective number of species".

We have computed values of "effective numbers" for taxonomic, functional and phylogenetic divergences, and Simpson's evenness for our data in order to assess their empirical complementarity/redundancy with $T D, P D, F D$ and Simpson's evenness.

We converted values of $T D, P D$ and $F D$ into "effective number" using the following formula:

$$
Q J o s t=\frac{1}{1-Q}
$$

where $\mathrm{Q}$ is the quadratic entropy computed by the classic formula. This transformation yields the 'effective numbers' of species in the sample if all species were equally abundance and maximally distinct (e.g. (Lefcheck and Buchheister, 2014) for an application). As for traditional indices, because the species distances are between 0 and 1, "effective number" of $T D, P D$ and $F D$ can be compared to each other.

In the cases of Simpson's evenness, we calculated the RLE as defined in (Jost, 2006): 


$$
R L E=\frac{\ln \left(\frac{1}{D}\right)}{\ln (S)}
$$

Our results unequivocally show that "effective numbers" indices are highly correlated to classical formula we used, with Spearman correlation coefficient ranging between 0.98 and 1 (Fig. 1). Thus, in addition to caution in the use of "effective numbers" concept from an ecological point of view (see (Gaertner et al., 2013), this result confirms that the use of traditional formula of indices we considered are sufficient (and represent well the response of "effective numbers" indices).

\begin{tabular}{|l|l|l|l|l|l|l|}
\hline & & & & & & \\
\hline
\end{tabular}


Fig. B3. The pairwise relationship is in the upper panel, the red line represents a local weighted regression ("loess"), the Spearman correlation coefficient in the lower panel, and the marginal distribution for each index in the diagonal. $S$ is species richness; $T D, F D, P D$ are taxonomic, functional and phylogenetic divergences respectively; Simps even is Simpson's evenness; TD Jost, FD Jost, PD Jost, RLE represent the "Effective numbers" for taxonomic, functional and phylogenetic divergences and for Simpson's evenness; indices are computed on a list of 134 species (see materials and methods section).

References:

Gaertner, J.-C., Maiorano, P., Mérigot, B., Colloca, F., Politou, C.-Y., Gil De Sola, L., Bertrand, J. a, Murenu, M., Durbec, J.-P., Kallianiotis, A., Mannini, A., 2013. Large-Scale Diversity of Slope Fishes: Pattern Inconsistency between Multiple Diversity Indices. PLoS One 8, e66753.

Jost, L., 2006. Entropy and diversity. Oikos 113, 363-375.

Lefcheck, J., Buchheister, A., 2014. Dimensions of biodiversity in Chesapeake Bay demersal fishes: patterns and drivers through space and time. Ecosphere 5, 1-48.

Villéger, S., Mason, N., Mouillot, D., 2008. New multidimensional functional diversity indices for a multifaceted framework in functional ecology. Ecology 89, 2290-301. 


\section{Appendix C. List of functional traits included in the study}

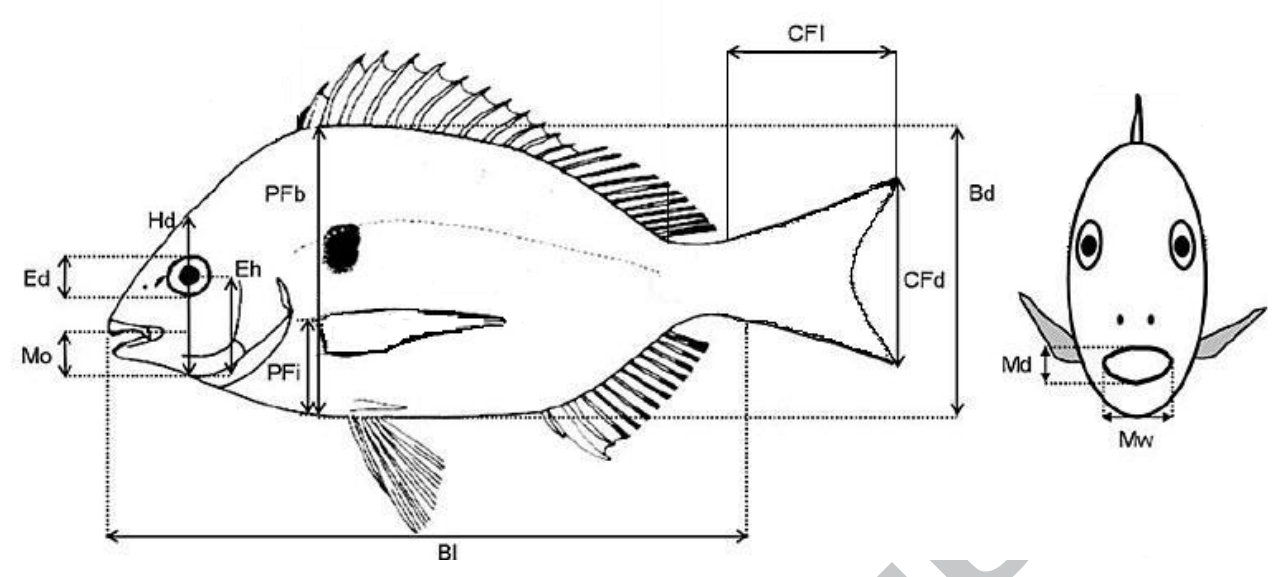

Fig. C1. Morphological measures used to compute functional traits (modified from supplementary information of (Villéger et al., 2010)). Bd: Longest body depth; Bl: Body standard length; CFd: caudal fin depth; CFl: caudal fin length; Ed: eye diameter; Eh: distance between the bottom of the head and the eye center along the head depth axis; Hd: head depth along the vertical axis of the eye; Mo: distance bottom of head-mouth; Md: mouth depth; Mw: mouth width; PFb: body depth at the level of the pectoral fin insertion; PFi: distance between the insertion of pectoral fin and the bottom of the body The three following functional traits have also been considered (not shown on the above figure):

Pigmentation on the fish body (silvery reflective side; countershading with dark lateral band, mottled pattern or vertical bars, countershading without either silveriness or lateral band);

Fish body shape (fusiform, compressed, round, filiform, depressed, gobiform);

Presence of barbel near the mouth (presence/absence) 
Description and interpretation of 11 functional traits derived from morphological measures

\begin{tabular}{|c|c|c|}
\hline Functional trait & Calculation & Functional interpretation \\
\hline Body & $\mathrm{Bl} / \mathrm{Bd}$ & $\begin{array}{l}\text { Hydrodynamic ability and metabolism of fish } \\
\text { species ((Sibbing and Nagelkerke, 2001), also } \\
\text { used in (Reecht et al., 2013), (Dumay et al., } \\
\text { 2004)) }\end{array}$ \\
\hline Caudal length & $\mathrm{CFl} / \mathrm{CFd}$ & $\begin{array}{l}\text { Fish swimming ability ((Sibbing and } \\
\text { Nagelkerke, 2001), also used in (Dumay et al., } \\
\text { 2004)) }\end{array}$ \\
\hline Eye size & $\mathrm{Ed} / \mathrm{Hd}$ & $\begin{array}{l}\text { Prey detection ((Boyle and Horn, 2006), also } \\
\text { used in (Lefcheck and Buchheister, 2014; } \\
\text { Villéger et al., 2010)) }\end{array}$ \\
\hline Eye position & $\mathrm{Eh} / \mathrm{Hd}$ & $\begin{array}{l}\text { Vertical position in the water column } \\
\text { ((Mahon, 1984; Watson and Balon, 1984), } \\
\text { also used in (Lefcheck and Buchheister, } \\
\text { 2014)) }\end{array}$ \\
\hline $\begin{array}{l}\text { Pectoral fin } \\
\text { position }\end{array}$ & $\mathrm{Pfi} / \mathrm{PFb}$ & $\begin{array}{l}\text { Pectoral fin use for and maneuverability } \\
\text { ((Dumay et al., 2004), also used in (Albouy et } \\
\text { al., 2011)) }\end{array}$ \\
\hline Mouth depth & $\mathrm{Md}$ & $\begin{array}{l}\text { Nature and size of food items captured } \\
\text { ((Sibbing and Nagelkerke, 2001), also used in } \\
\text { (Lefcheck and Buchheister, 2014)) }\end{array}$ \\
\hline Mouth width & $\mathrm{Mw}$ & $\begin{array}{l}\text { Nature and size of food items captured } \\
\text { ((Sibbing and Nagelkerke, 2001), also used in } \\
\text { (Lefcheck and Buchheister, 2014)) }\end{array}$ \\
\hline Oral gap position & $\mathrm{Mo} / \mathrm{Hd}$ & $\begin{array}{l}\text { Feeding method in the water column } \\
\text { ((Sibbing and Nagelkerke, 2001), also used in } \\
\text { (Albouy et al., 2011; Dumay et al., 2004; } \\
\text { Lefcheck and Buchheister, 2014)) }\end{array}$ \\
\hline Barbel & $\begin{array}{l}\text { The presence of barbel near } \\
\text { the mouth }\end{array}$ & $\begin{array}{l}\text { Benthic macroinvertebrate detection for } \\
\text { consumption ((Piet, 1998), also used in } \\
\text { (Reecht et al., 2013)) }\end{array}$ \\
\hline Pigmentation & Pigmentation of the body & Indicates habitat and behaviour [11] \\
\hline Body shape & Fish body shape & Fish swimming ability [12] \\
\hline
\end{tabular}

\section{References}

1. Villéger S, Miranda JR, Hernández DF, Mouillot D (2010) Contrasting changes in taxonomic vs. functional diversity of tropical fish communities after habitat degradation. Ecol. Appl. 20: 1512-1522.

2. Sibbing F a, Nagelkerke L a J (2001) Resource partitioning by Lake Tana barbs predicted from fish morphometrics and prey characteristics. Rev. Fish Biol. Fish. 10: 393-437.

3. Reecht Y, Rochet M-J, Trenkel VM, Jennings S, Pinnegar JK (2013) Use of morphological characteristics to define functional groups of predatory fishes in the Celtic Sea. J. Fish Biol. 83: 355-77.

4. Dumay O, Tari PS, Tomasini J a., Mouillot D (2004) Functional groups of lagoon fish species in Languedoc Roussillon, southern France. J. Fish Biol. 64: 970-983. 
5. Boyle K, Horn M (2006) Comparison of feeding guild structure and ecomorphology of intertidal fish assemblages from central California and central Chile. Mar. Ecol. Prog. Ser. 319: 65-84.

6. Lefcheck J, Buchheister A (2014) Dimensions of biodiversity in Chesapeake Bay demersal fishes: patterns and drivers through space and time. Ecosphere 5: 1-48.

7. Mahon R (1984) Divergent Structure in Fish Taxocenes of North Temperate Streams. Can. J. Fish. Aquat. Sci. 41: 330-350.

8. Watson DJ, Balon EK (1984) Ecomorphological analysis of fish taxocenes in rainforest streams of northern Borneo. J. Fish Biol. 25: 371-384.

9. Albouy C, Guilhaumon F, Villéger S, Mouchet M, Mercier L, et al. (2011) Predicting trophic guild and diet overlap from functional traits: statistics, opportunities and limitations for marine ecology. Mar. Ecol. Prog. Ser. 436: 17-28.

10. Piet GJ (1998) Ecomorphology of a size-structured tropical freshwater fish community. Environ. Biol. Fishes 51: 67-86.

11. Nikolskii GV (1963) The ecology of fishes. $2^{\text {nd }}$ edition. Academic Press, New York. 352 p.

12. Webb PW (1984) Form and function in fish swimming. Scientific American 251:72-82. 
Appendix D. Draftsman's plot of diversity indices computed on 19,886 hauls on a list of 186 species

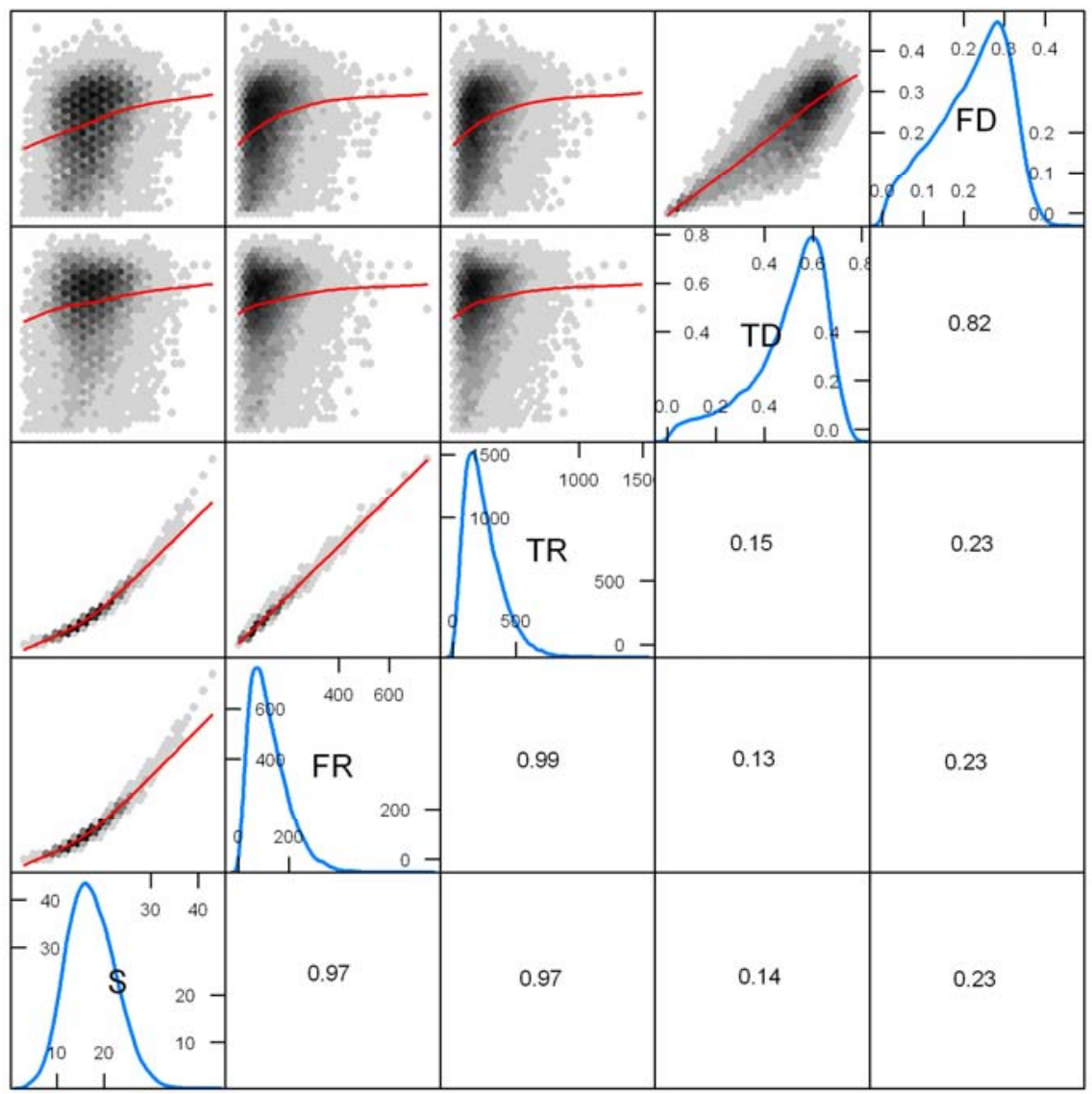

Fig. D1. The pairwise relationship is in the upper panel, the red line represents a local weighted regression ("loess"), the Pearson correlation coefficient in the lower panel, and the marginal distribution for each index in the diagonal. $S$ is species richness; $T D$ and $F D$ are taxonomic and functional divergences respectively; and $T R$ and $F R$ are taxonomic and functional richness, computed by the modified Rao's quadratic entropy $Q+$ on fish presence/absence data. 


\section{Appendix E. GLM and Regression tree models (CART) investigating spatio-temporal variability of species richness $S$ and functional divergence $F D$}

Table E1. Generalized linear models for $S$ and $F D$. Indices measured per haul (i.e $\alpha$-diversity) on19886 hauls for 19 years in 7 biogeographical zones (BGZ) or 2 basins in the Mediterranean Sea. GLM including both Year and Bassin or BGZ as explicative factors, with a Normal and Gamma error distributions, were considered for $S$ and 1-FD respectively.

Percentages represent the part of deviance explained by each variable in the same model, with degrees of freedom into brackets. All effects are significant $(\mathrm{p}<0.05)$. Note that $S$ computed per GSA was rarefied to 25 hauls for accurate comparison (see materials and methods section).

\begin{tabular}{|c|c|c|c|c|c|c|}
\hline & & Total & BGZ & Year & BGZ:Year & Raref \\
\hline \multirow[t]{2}{*}{$S$} & $\alpha$-diversity & $11,34 \%$ & $6,58 \%(6)$ & $1,74 \%$ & $3,01 \%(87)$ & \\
\hline & $\gamma$-diversity & $54,21 \%$ & $46,7 \%(6)$ & $7,74 \%(18)$ & a & 25 \\
\hline \multirow{3}{*}{$S$} & & Total & Bassin & Year & Bassin:Year & Raref \\
\hline & $\alpha$-diversity & $3,80 \%$ & $1,1 \%(1)$ & $2,07 \%(18)$ & $<1 \%$ & \\
\hline & $\gamma$-diversity & & $7,91 \%(1)$ & $7,74 \%$ (18) & a & 25 \\
\hline \multirow{3}{*}{$1-F D$} & & Total & BGZ & Year & BGZ:Year & Raref \\
\hline & $\alpha$-diversity & $3,65 \%$ & $1,0 \%(6)$ & $0,5 \%$ (18) & $2,1 \%(87)$ & \\
\hline & $\gamma$-diversity & $7,55 \%$ & $2,04 \%(6)$ & $5,52 \%(18)$ & a & No raref \\
\hline \multirow{3}{*}{$1-F D$} & & Total & Basin & Year & Bassin:Year & Raref \\
\hline & $\alpha$-diversity & $<1 \%$ & $0,2 \%(1)$ & $0,5 \%(18)$ & $0,2 \%(18)$ & \\
\hline & $\gamma$-diversity & $5,65 \%$ & $<1 \%(1)$ & $5,57 \%(18)$ & a & No raref \\
\hline
\end{tabular}

${ }^{a}$ Models for species richness per GSA do not include interaction, as one value per BGZ (or basin) and per year is available. 
a)

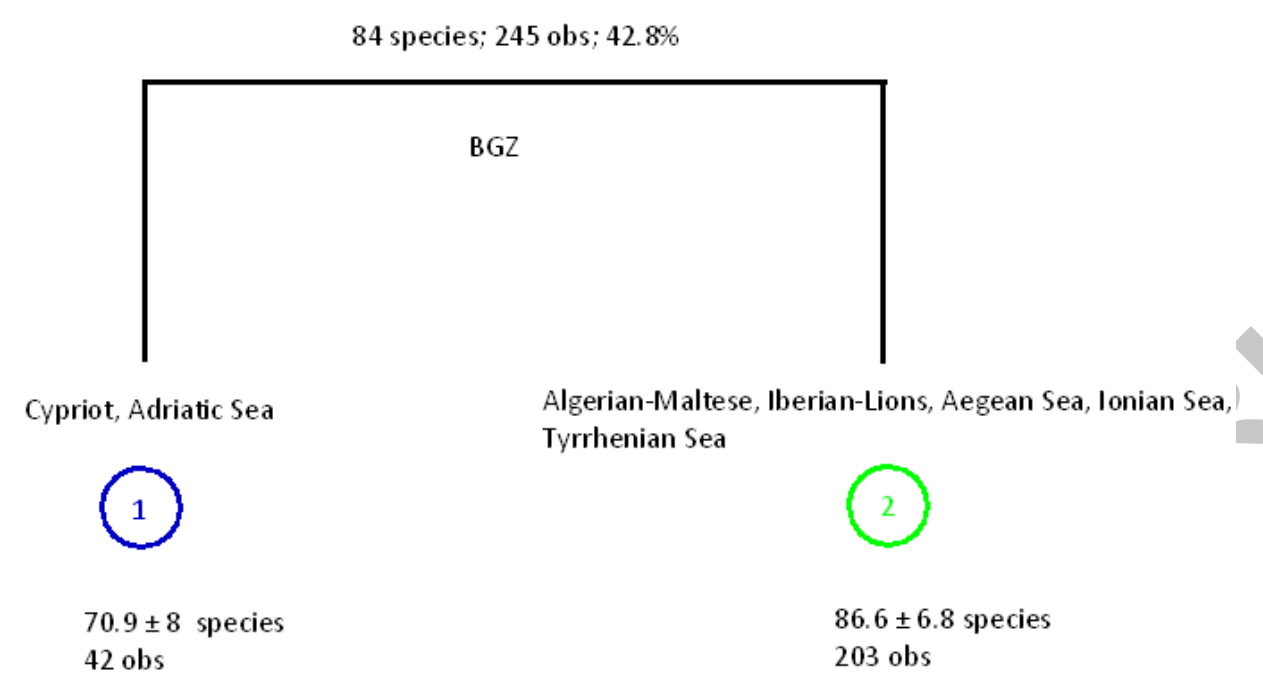

b)

17.35 species; 19886 hauls; $5.5 \%$

BGZ

n-Maltese, Cypriot, Adriatic Sea, Ionian Sea,

Tyrrhenian Sea

Iberian-Lions, Aegean Sea

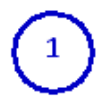

$16.6 \pm 4.7$ species 14877 hauls

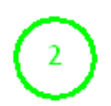

$19.4 \pm 5.3$ species 5009 hauls

Fig. E1. Regression tree models for $S$. Values computed (a) per GSA (i.e. $\gamma$-diversity), and (b) per haul (i.e. $\alpha$-diversity) across the Mediterranean Sea. The splitting variable

(Biogeographical zones BGZ and Year) and its modalities value (see Fig.1) are shown on each branch (horizontal lines). The terminal nodes show the $S$ mean values, number of observations (obs, i.e. rarified $S$ values) and hauls from which the mean values have been computed for $\gamma$ and $\alpha$-diversity, respectively. 
Table E2. Indices measured per biogeographical zone (i.e. $\gamma$-diversity) on 19,886 hauls for 19 years of the Mediterranean Sea in 7 biogeographical zones (BGZ) or 2 basins in the Mediterranean Sea. GLM including both Year and Bassin or BGZ as explicative factors, with a Normal and Gamma error distributions were considered for $S$ and $1-F D$ respectively. Percentages represent the part of deviance explained by each variable in the same model, with degrees of freedom into brackets. All effects are significant $(\mathrm{p}<0.05)$. Note that $S$ computed per BGZ was rarefied to 45 hauls for accurate comparison (see materials and methods section).

\begin{tabular}{lllllll}
\hline & & Total & BGZ & Year & BGZ:Year & Raref \\
\hline$S$ & per BGZ & $75 \%$ & $67,60 \%$ & $7,40 \%$ & - & 45 \\
$1-F D$ & per BGZ & $23,7 \%$ & $3,80 \%$ & $19,20 \%$ & -- & No raref \\
& & & & & & \\
& & Total & Basin & Year & Basin:Year & Raref \\
$S$ & per BGZ & $38,50 \%$ & $28,70 \%$ & $10,40 \%$ & -- & 45 \\
$1-F D$ & per BGZ & $20,00 \%$ & $1,00 \%$ & $19,00 \%$ & -- & No raref \\
\hline
\end{tabular}




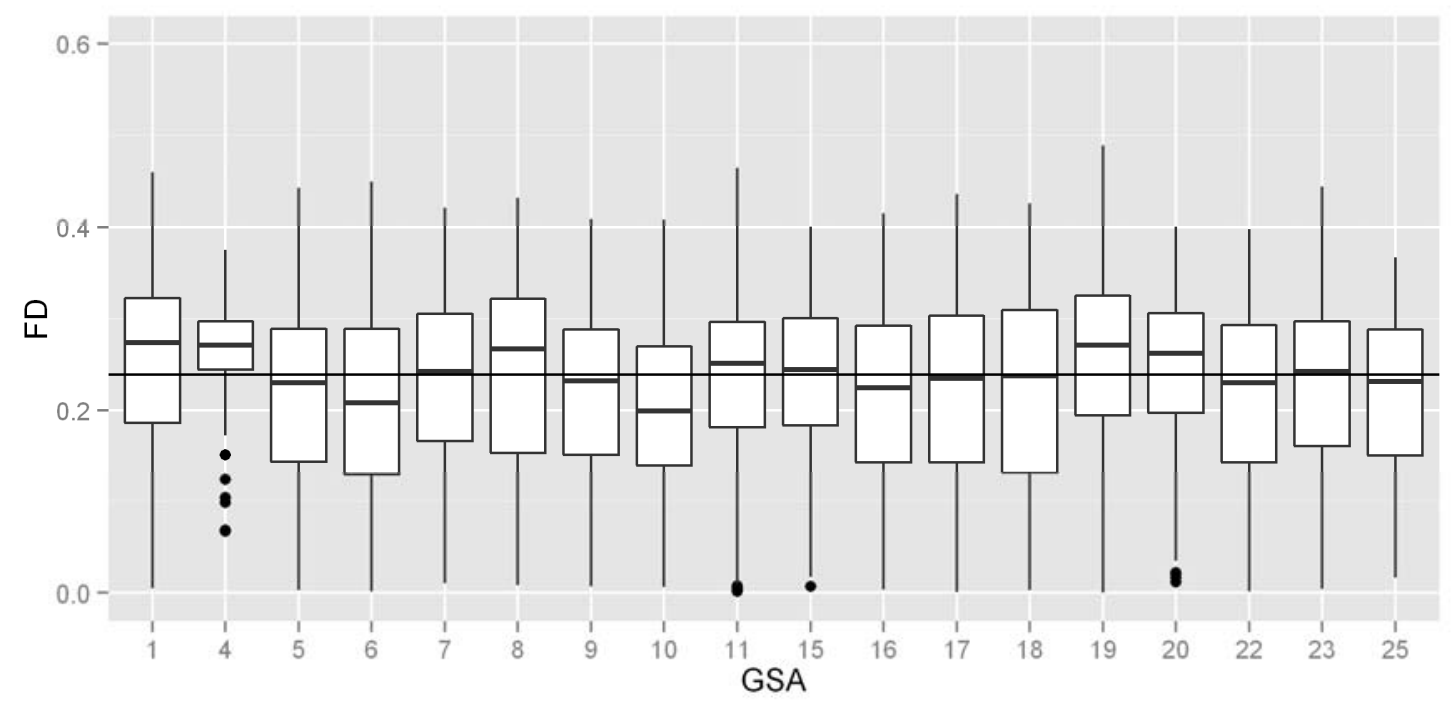

Fig. E2. Boxplot for spatial variability between MEDITS GSAs of functional divergence $F D$ all years mingled. Red line represents overall median of $F D$. Index measured per haul ( $\alpha-$ diversity) on a list of 134 species for 19,886 hauls (see materials and methods section). 
Appendix F. Rao's quadratic entropy decomposition (divergences indices).

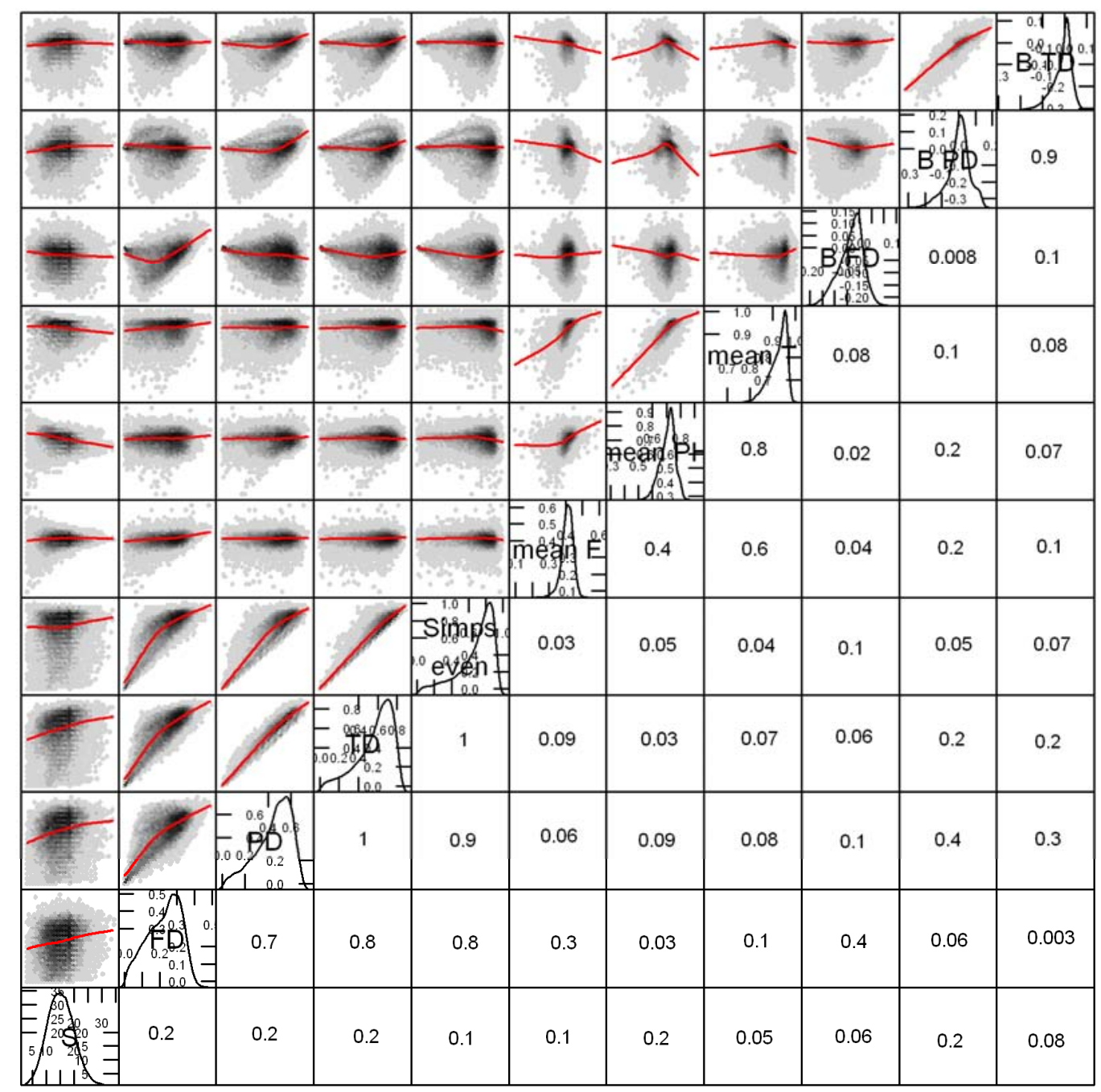

Fig. F1. The pairwise relationship is in the upper panel, the red line represents a local weighted regression ("loess"), the Pearson correlation coefficient in the lower panel, and the marginal distribution for each index in the diagonal. $S$ is species richness; TD/PD/FD are taxonomic, phylogenetic, functional divergences respectively, computed by Rao's quadratic entropy $Q$ on fish abundance data; mean $\mathrm{F} /$ mean $\mathrm{PH} /$ mean $T$ are mean taxonomic, functional divergences distances per haul respectively computed by formula below; and Simps even 
represents the evenness; indices are computed on the list of 134 species (see materials and methods section).

The quadratic entropy $Q$ is equal to (Pavoine et al., 2013; Shimatani, 2001) :

$$
Q=\operatorname{mean} D^{*} G+B
$$

Where $G$ is the Gini-Simpson index, mean $D$ is defined bellow and $B$ is defined as:

$$
B=2 \sum_{i<j}^{S}\left(d_{i j}-m e a n D\right)\left(p_{i} p_{j}-\tilde{G}\right)
$$

where :

$$
\widetilde{G}=\frac{G}{S(S-1)}
$$

and Mean D which represents functional /phylogenetic/ taxonomic distance defined as :

$$
\text { meanD }=\frac{1}{S(S-1)} * \sum_{i=1}^{S} \sum_{j=1}^{S} d_{i j}
$$

$S$ is the number of species in the haul, $d_{i j}$ the phylogenetic, or functional or taxonomic difference between two species $i$ and $j$ stored in a distance matrix. Mean $D$ index corresponds to the average pair-wise functional or phylogenetic or taxonomic distances between species in an assemblage.

\section{References:}

Pavoine, S., Gasc, A., Bonsall, M.B., Mason, N.W.H., 2013. Correlations between phylogenetic and functional diversity: mathematical artefacts or true ecological and evolutionary processes? J. Veg. Sci. 24, 781-793.

Shimatani, K., 2001. On the measurement of species diversity incorporating species differences. Oikos 93, 135147. 
Highlights:

- We analyse fish diversity by a multiple indices and scales approach over 19 years

- Species richness and evenness are proxies of phylogenetic and functional components

- Species richness reveals hotspots for different spatial scales contrary to evenness

- All diversity components remains stable over the last two decades 